OPEN ACCESS

Edited by:

Bingyun Li,

West Virginia University, United States

Reviewed by:

Qingquan Chen,

Stanford University, United States Volker Behrends,

University of Roehampton London, United Kingdom

*Correspondence:

Y. Peter D

peterdi@pitt.edu

Specialty section:

This article was submitted to

Antimicrobials, Resistance

and Chemotherapy,

a section of the journal

Frontiers in Microbiology

Received: 26 July 2021

Accepted: 20 October 2021

Published: 19 November 2021

Citation:

Lin Q, Pilewski JM and Di YP

(2021) Acidic Microenvironment

Determines Antibiotic Susceptibility and Biofilm Formation

of Pseudomonas aeruginosa.

Front. Microbiol. 12:747834.

do: $10.3389 /$ fmicb.2021.747834

\section{Acidic Microenvironment Determines Antibiotic Susceptibility and Biofilm Formation of Pseudomonas aeruginosa}

\author{
Qiao Lin', Joseph M. Pilewski and Y. Peter Di1* \\ ${ }^{1}$ Department of Environmental and Occupational Health, University of Pittsburgh, Pittsburgh, PA, United States, ${ }^{2}$ Division of \\ Pulmonary, Allergy, and Critical Care Medicine, Department of Medicine, University of Pittsburgh, Pittsburgh, PA, \\ United States
}

Pseudomonas aeruginosa is the most prevalent bacterial species that contribute to cystic fibrosis (CF) respiratory failure. The impaired function of CF transmembrane conductance regulator leads to abnormal epithelial $\mathrm{Cl}^{-} / \mathrm{HCO}_{3}{ }^{-}$transport and acidification of airway surface liquid. However, it remains unclear why the CF lung is most commonly infected by Pseudomonas aeruginosa versus other pathogens. We carried out studies to investigate if lower $\mathrm{pH}$ helps Pseudomonas aeruginosa adapt and thrive in the CF-like acidic lung environment. Our results revealed that Pseudomonas aeruginosa generally forms more biofilm, induces antibiotic resistance faster in acidic conditions, and can be reversed by returning the acidic environment to physiologically neutral conditions. Pseudomonas aeruginosa appears to be highly adaptive to the CFlike acidic pH environment. By studying the effects of an acidic environment on bacterial response, we may provide a new therapeutic option in preventing chronic Pseudomonas aeruginosa infection and colonization.

Keywords: cystic fibrosis - CF, Pseudomonas aeruginosa, antibiotic resistance, bacterial evolution, acidic pH

\section{INTRODUCTION}

Cystic fibrosis (CF) is a genetic disease involving compromised function of cystic fibrosis transmembrane conductance regulator (CFTR) that leads to impaired airway host defense and therefore causes lung inflammation and bacterial infections (Pezzulo et al., 2012; Shah et al., 2016). The environment in CF lungs is thought to be acidic, as evidenced by the lower-thanneutral $\mathrm{pH}$ value of the airway surface liquid (ASL) in newborn CF pigs and differentiated human and porcine primary epithelial cell cultures, compared to non-CF controls (Pezzulo et al., 2012; Shah et al., 2016). The malfunction of CFTR also leads to elevated $\mathrm{Na}^{+}$and $\mathrm{Cl}^{-}$levels in the airway, inhibiting the natural antimicrobial factors in ASL (Zabner et al., 1998). Pseudomonas aeruginosa ( $P$. aeruginosa) is an opportunistic Gram-negative pathogen that is the most prevalent bacterial species in adult CF lungs and contributes to the associated high mortality rates (Silva Filho et al., 2013). The prevalence of $P$. aeruginosa lung infection gradually increases over time from approximately $20 \%$ to $70 \%$ in CF patients from age 2 to 45 (Cystic Fibrosis Foundation, 2020), which coincides with an increase in CF disease severity. Bacteria expand their population in the natural environment and the host via two different forms. The planktonic form of free-moving bacteria is the typical way bacteria spread themselves at the initial stage of reaching a new environment. In contrast, the accumulated form 
of bacteria, so-called "biofilm," represents another critical pathogenic mechanism. It is noted that the bacterial biofilm formation in the CF airway likely contributes to the chronic colonization of $P$. aeruginosa (Lyczak et al., 2002).

Many factors contribute to CF airway acidification, and there are adverse health consequences. From the bacterial perspective, it has been reported that extracellular DNA (eDNA) is the most abundant polymer within the $P$. aeruginosa biofilm matrix (Matsukawa and Greenberg, 2004; Okshevsky and Meyer, 2015). Previous studies suggested that eDNA acidifies $P$. aeruginosa biofilm and promotes resistance to aminoglycoside antibiotics (Wilton et al., 2016). Studies also demonstrated that when $P$. aeruginosa is under acidic stress, the bacterial outer membrane permeability (PhoPQ/PmrAB-controlled surface modifications) could decrease and result in decreased antibiotic uptake (Adewoye and Worobec, 1999; Wilton et al., 2016). Additionally, acidic $\mathrm{pH}$ likely modulates aminoarabinose-modified LPS and spermidine, which mask bacterial negative surface charges and block the entrance of aminoglycosides (Ernst et al., 2007; Johnson et al., 2012; Wilton et al., 2016). Our results demonstrated that $P$. aeruginosa grew under other classes of antibiotics $(\beta$-lactam and fluoroquinolone), in addition to the previously published aminoglycosides (Wilton et al., 2016), also increase the acquired antibiotic tolerance. Currently, known mechanisms could partly explain why acidic $\mathrm{pH}$ induces immediate antibiotic tolerance, but the long-term impact of acidic $\mathrm{pH}$ on bacterial evolution with antibiotic treatment remained unknown. From the host perspective, the CF lung is burdened with acidic eDNA originated from the immune cells recruited by chronic bacterial infections (Lethem et al., 1990). In addition, Shah et al. (2016) reported evidence that the non-gastric $\mathrm{H}+/ \mathrm{K}+$ adenosine triphosphatase (ATP12A), a proton pump that actively acidifies human and porcine airways, is absent in mice. This explains why CFTRdeficient mice with no acidic airway epithelium are free from opportunistic respiratory infections.

The evidence of CF airway acidification and the high prevalence of $P$. aeruginosa among CF lung infections prompted us to determine the effects of a CF-like acidic environment on the pathogenic ability of $P$. aeruginosa. Our results indicated that the acidic environment stimulates increased $P$. aeruginosa biofilm formation, promotes faster bacterial evolution toward elevated antibiotic resistance as evidenced by stable genetic mutations, and increases expressions of multiple biofilm/virulence-related genes. Interestingly, based on our observation, $P$. aeruginosa was the only bacterial species from the notorious ESKAPE pathogens (Enterococcus faecium, Staphylococcus aureus, Klebsiella pneumoniae, Acinetobacter baumannii, Pseudomonas aeruginosa, and Enterobacter spp.) that showed a pattern of increased biofilm formation in acidic conditions. Furthermore, the acidic environment on the apical surface of differentiated primary bronchial epithelial cells isolated from CF patients (CFBEs) results in increased $P$. aeruginosa attachment and bacterial numbers than the physiologically neutral environment on the surface of cultured primary human bronchial epithelial cells from normal subjects (HBEs). These adverse effects of a CF-like acidic environment can be ameliorated by modulating the acidic environment into physiologically neutral conditions. The varying characteristics and behavior of $P$. aeruginosa in different $\mathrm{pH}$ conditions may provide additional treatment targets and options for CF sufferers in preventing chronic $P$. aeruginosa infection and colonization.

\section{RESULTS}

\section{The Response of Pseudomonas aeruginosa to Cystic Fibrosis-Like Microenvironment}

Pseudomonas aeruginosa gradually increases its presence in the CF airways after the pathological phenotypes of CFTR malfunction appear more obviously with the increased age of the CF sufferers (Cystic Fibrosis Foundation, 2020). It is welldocumented that compromised functions of CFTR and the CFTR-modulated $\mathrm{HCO}_{3}{ }^{-}$secretion in $\mathrm{CF}$ result in an abnormal environment of higher salt ( $\sim 100 \pm 5 \mathrm{mM})$ (Zabner et al., 1998) and lower $\mathrm{pH}(\sim 6.7 \pm 0.3)$ (Chen et al., 2010; Pezzulo et al., 2012; Shah et al., 2016) in the CF ASL than those of normal subjects.

We first examined the effects of salt concentration and acidic condition on bacterial planktonic and biofilm mode of growth to understand the effects of the CF-like microenvironment on the behavior of $P$. aeruginosa. Two widely used $P$. aeruginosa lab strains (PAO1 and PA14) and two multi-drug resistant (MDR) $P$. aeruginosa clinical strains isolated from CF patients (P.a. 129-5 and P.a. 152-19) were selected for this experiment. The growth curves indicated that various salt concentrations (addition of 50,100, and $150 \mathrm{mM} \mathrm{NaCl}$ ) and $\mathrm{pH}$ conditions $(\mathrm{pH}=6.0,6.5,7.0$, and 7.5 adjusted by $\mathrm{HCl})$ did not result in any noticeable difference in the proliferation rate of planktonic $P$. aeruginosa in all four strains (Supplementary Figure S1). There was less biofilm biomass formed with the increasing $\mathrm{NaCl}$ concentrations in PAO1. In contrast, the effect of salt concentrations on biofilm formation was not apparent in the other three $P$. aeruginosa strains (Supplementary Figure S2). Nonetheless, we observed significant changes in the initial attachment of bacterial biofilm under acidic $\mathrm{pH}$ conditions after just $3 \mathrm{~h}$ of incubation (Supplementary Figure S2). Except for PA14, all the other three tested $P$. aeruginosa strains showed similar results of increased attachment of bacteria at acidic $(\mathrm{pH}<7)$ conditions within each tested $\mathrm{NaCl}$ concentration group. These results suggest that the acidic environment likely promoted the initial attachment of $P$. aeruginosa.

\section{Increased Pseudomonas aeruginosa Antibiotic Tolerance Under Acidic pH Conditions}

It is known that common antibiotic treatments such as inhaled tobramycin and ceftazidime in CF respiratory infections do not guarantee respiratory $P$. aeruginosa eradication (MayerHamblett et al., 2012; Cystic Fibrosis Foundation, 2020). Thus, we sought to determine if the CF-like acidic environment enhanced bacterial tolerance to antibiotics. Three different classes of commonly used standard-of-care antibiotics, including ceftazidime ( $\beta$-lactam), ciprofloxacin (fluoroquinolone), and 
tobramycin (aminoglycosides), each with a distinct antibacterial mechanism, were tested against the same four bacterial strains of $P$. aeruginosa at their respective MICs (at physiologically neutral $\mathrm{pH}$ 7.5) under different $\mathrm{pH}$ conditions. Our results indicated that the acidic $\mathrm{pH}$ environment alone does not notably change the $P$. aeruginosa proliferation rate (Figure 1A). However, acidic conditions increased bacterial tolerance to all three clinically used antibiotics, as demonstrated in the elevated growth curves compared to $\mathrm{pH} 7.5$ when the same dosage of each antibiotic was used in all varying $\mathrm{pH}$ conditions (Figure 1B). In all cases, $P$. aeruginosa grown under the acidic conditions $(\mathrm{pH}=6.0$ and $\mathrm{pH}=6.5$ ) demonstrated higher tolerance to the antibiotic treatments as their growth curves were closer to those of the "no antibiotic treatment" controls. The slope of the growth curve gradually decreases as the $\mathrm{pH}$ value increases. To determine if the increased bacterial growth in lower $\mathrm{pH}$ conditions was due to permanent degradation or temporary inactivation of antibiotics in the acidic environment, we pre-incubated the antibiotics in physiologically neutral $\mathrm{pH} 7.5$ or acidic $\mathrm{pH}$
6.0 for $5 \mathrm{~h}$ before the bacterial growth kinetic experiments. Interestingly, the antibiotics pre-exposed to $\mathrm{pH} 6.0$ and $\mathrm{pH}$ 7.5 showed similar growth inhibition curves when the growth inhibition assay (GIA) was performed at the $\mathrm{pH} 7.5$ condition (Supplementary Figure S3). The results indicated that antibiotics pre-exposed to acidic conditions $(\mathrm{pH}=6.0)$ did not lose their drug potency and regained their antibacterial activity after returning to the physiologically neutral condition $(\mathrm{pH}=7.5$ ). These data suggested that $P$. aeruginosa could quickly become more tolerant to antibiotic treatment in an acidic environment.

\section{Increased Pseudomonas aeruginosa Antibiotic Resistance Under Acidic pH Conditions}

To further explore if acidic $\mathrm{pH}$ promotes $P$. aeruginosa antibiotic resistance, we carried out studies to investigate bacterial evolution with antibiotics in acidic and neutral $\mathrm{pH}$ conditions. Both biofilm and planktonic $P$. aeruginosa were grown under the
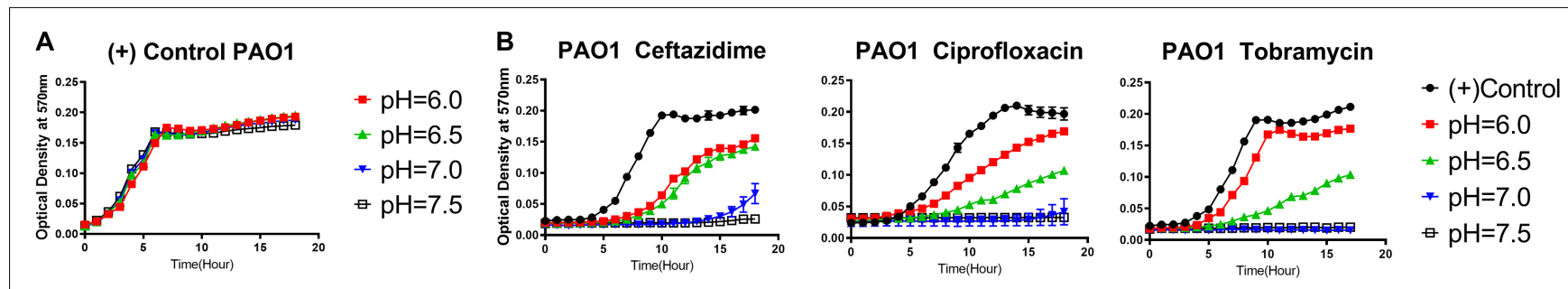

(+) Control PA14
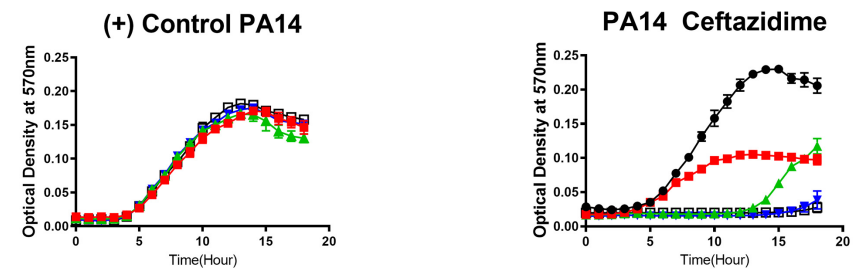

PA14 Ciprofloxacin

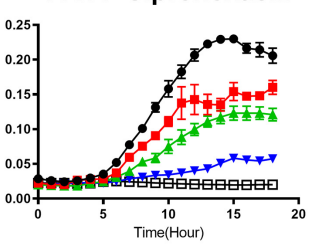

PA14 Tobramycin

(+) Control P.a. 129-5

P.a. 129-5 Ceftazidime
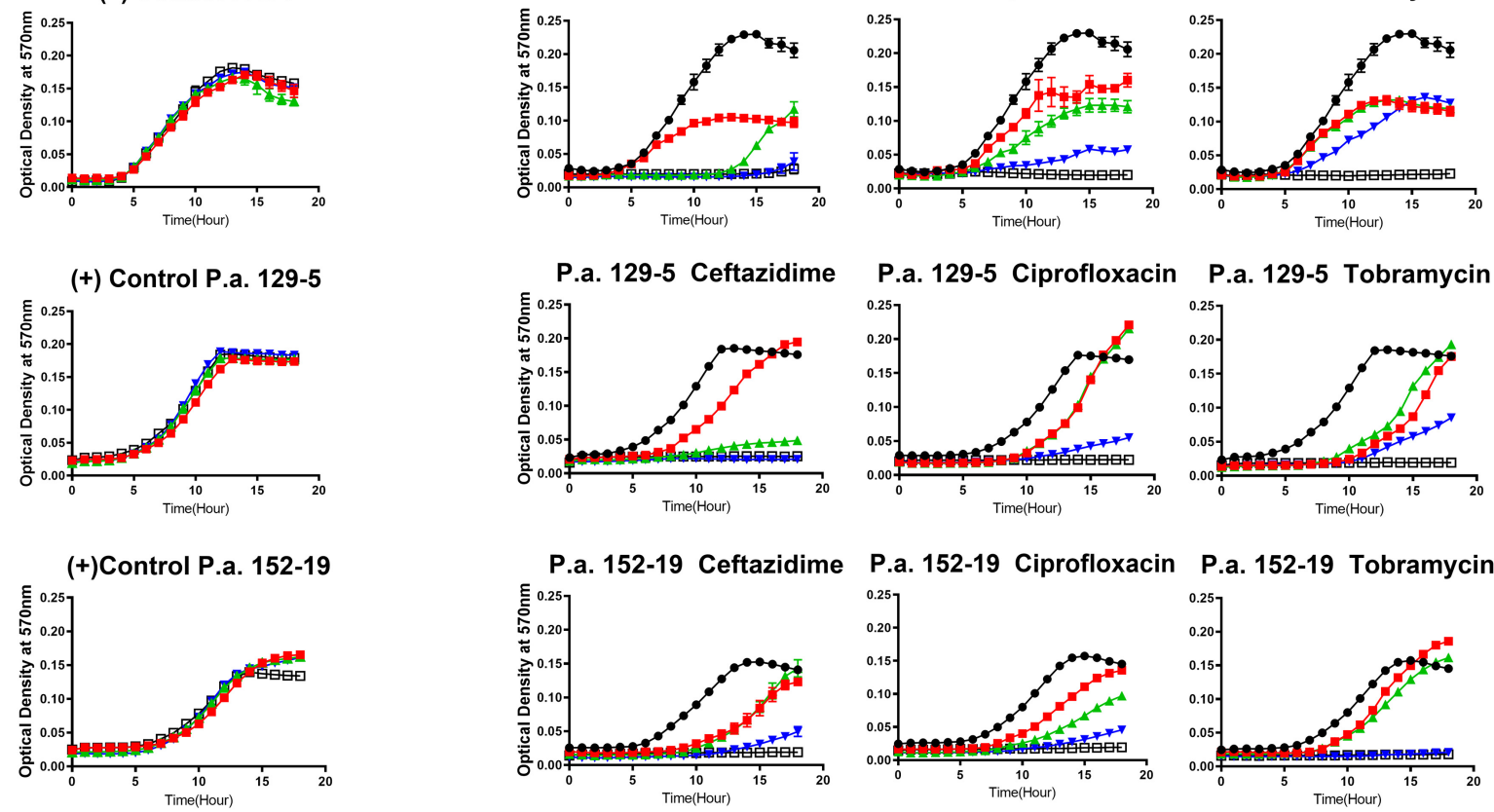

FIGURE 1 | Acidic pH conditions impair the antimicrobial activity of standard-of-care antibiotics against $P$. aeruginosa. (A) $P$. aeruginosa growth curve in pH adjusted, antibiotic-free medium. (B) $P$. aeruginosa growth curve in $\mathrm{pH}$ adjusted medium, supplemented with ceftazidime, ciprofloxacin, and tobramycin at the respective MIC for each antibiotic at pH 7.5. A pH-adjusted 10\% TSB medium was used in this experiment. Optical density at $570 \mathrm{~nm}$ was measured every hour for $18 \mathrm{~h}$ at $37^{\circ} \mathrm{C}$ in a microplate reader. A closely fitted lid was placed on the microplate to prevent liquid evaporation. No samples were placed near the edge of the 96-well microplate to prevent any drying effect during overnight incubation. Results are mean \pm SEM from three independent experiments with bacteria grew in duplicates for each condition. 
treatment of ceftazidime, ciprofloxacin, and tobramycin, three of the most commonly used antibiotics in treating CF respiratory infection. The reference strain of $P$. aeruginosa (PA14) was selected because we sought to focus on investigating the $\mathrm{pH}$ effect without concerns of horizontally transferred plasmids or bacteriophages that could exist in clinical strains. The $P$. aeruginosa biofilm was generated by growing PA14 on acrylic beads and transferred daily to a new culture tube with a new sterile bead in the existence of antibiotics (Figure 2A). The planktonic culture served as a control of the biofilm evolution model in contrasting the different growth modes (Figure 2B). The new MIC of each PA14 culture condition was determined daily by the survival of each population after $24 \mathrm{~h}$ of incubation in a fresh medium containing doubled antibiotic concentrations. After 15 days of continuous growth and evolution, PA14 populations acquired increased levels of resistance against all three antibiotics. The acidic environment significantly increased the MIC required for the tested antibiotics to kill $P$. aeruginosa (Figures 2C-E), regardless of the antibiotic killing mechanisms.

Acidic pH environment induces immediate antibiotic tolerance of $P$. aeruginosa in planktonic growing conditions up to eightfold compared to a neutral $\mathrm{pH}$ environment (Supplementary Table S1). Furthermore, we observed a 32to 512-fold MIC increase in the acidic $\mathrm{pH}$ treated biofilm populations after 15 days of evolution (Figures 2C-E). Therefore, we hypothesized that PA14 underwent genetic mutations to survive antibiotic pressure, and the ceftazidime treated PA14 populations were selected for further analysis. Whole-genome sequencing (WGS) of the bacteria was performed in every testing bacterial population to identify the high-frequency mutations (Figure 2F). WGS of four randomly picked single colonies from each of the $\mathrm{pH} 6.5$ biofilm populations (B1-B3) were then carried out to directly determine the evolved genotypes in correspondence to the MIC-increasing phenotypes (Table 1). Common mutations on the efflux pump (mexB and mexR) known to induce ceftazidime resistance (Sanz-Garcia et al., 2018) were identified in half of $\mathrm{pH} 6.5$ populations and five out of six $\mathrm{pH} 7.5$ populations (Figure 2F). The mexB and mexR mutations conferred $\mathrm{pH} 6.5$ population $\mathrm{B} 2$ ceftazidime resistance a 64 -fold increase (Figure 2C), which was subsequently confirmed by clonal genotype (Figure 2G) and MIC (Table 1) of selected individual clones.

Interestingly, three out of six of the evolved bacterial populations under the $\mathrm{pH} 6.5$ conditions (biofilm and planktonic) generated antibiotic resistance to ceftazidime via efflux pump-independent mechanisms. For instance, the combined mutations in $\sec B$ and $d p p A 3$ resulted in an acidic $\mathrm{pH}$-inducible 64-fold MIC increase in the $\mathrm{pH} 6.5$ biofilm population B1 (Figure 2C) and a 64- to 94-fold MIC increase in individual clones (Figure 2G and Table 1). Mutations on spoT, argJ, and algZ potentially contributed to a 32 -fold MIC increase in the $\mathrm{pH} 6.5$ biofilm population $\mathrm{B} 3$ but in the selected individual clones only showed mild MIC increase (4- to 8-fold increase, Table 1), which indicated a common discrepancy in MIC due to bacterial lifestyle difference. The sequencing results indicated that the mutations generated from PA14 bacterial populations evolved without antibiotics (Figure $2 \mathbf{H}$ ) do not overlap with mutations identified under antibiotic selection (Figures 2F,G), which suggests that acidic $\mathrm{pH}$ condition is a critical factor in promoting the evolution of drug-resistance when antibiotics are present.

\section{Acidic Conditions Promote Biofilm Formation of Pseudomonas aeruginosa Clinical Isolates and Compromise Biofilm Prevention Activities of Antibiotics}

We further evaluated fourteen $P$. aeruginosa strains to validate the hypothesis that acidic $\mathrm{pH}$ promotes bacterial biofilm formation and impairs antibiotic efficacy. These include twelve clinical $P$. aeruginosa isolates obtained initially from CF patients and two standard lab strains (PAO1 and PA14). In Figure 3A, the CF-like, acidic pH 6.5 condition alone stimulated more mature biofilm formation from approximately $71 \%(10 / 14)$ of all $P$. aeruginosa strains compared to $\mathrm{pH} 7.5$. The difference is significant and more noticeable when 1x MIC of ceftazidime, ciprofloxacin, and tobramycin was used in $P$. aeruginosa biofilm prevention. In Figures 3B-D, $14 P$. aeruginosa strains were treated with antibiotics using their respective MIC dosages (Supplementary Table S1) in pH 6.5 and 7.5 conditions. The majority of antibiotic-treated $P$. aeruginosa strains formed more biofilm after $18 \mathrm{~h}$ in the $\mathrm{pH} 6.5$ condition compared to the pH 7.5 condition. These biofilm data are in accordance with our growth kinetic studies and the PA14 evolution studies (Figures 1, 2). All experiment results showed a similar pattern that ceftazidime, ciprofloxacin, and tobramycin were generally less effective in inhibiting $P$. aeruginosa growth and preventing biofilm formation at acidic $\mathrm{pH}$ conditions. All other five species of ESKAPE pathogens except $P$. aeruginosa conversely demonstrated decreased biofilm formation under acidic $\mathrm{pH}$ stress (Figure 3E).

\section{Neutralization of Acidic pH in Cystic Fibrosis Epithelial Cells Restores Impaired Host Defense}

Acidic pH impairs important host defense mechanisms such as the ASL antibacterial activities of antimicrobial peptides, including $\beta$-defensin-1, -3, and LL-37 (Johansson et al., 1998; Nakayama et al., 2002; Abou Alaiwa et al., 2014). Our results demonstrate that the acidic $\mathrm{pH}$ in the $\mathrm{CF}$-like microenvironment increases bacterial tolerance/resistance against antibiotics and enhances biofilm formation, which may promote $P$. aeruginosa colonization. To simulate the airway microenvironment, we further determined if the neutralization of the acidic ASL of differentiated human bronchial epithelial cells that were maintained under air-liquid interface (ALI) culture could help alleviate $P$. aeruginosa infection (Figure 4A). The primary human bronchial epithelial (HBE, non-CF) cells and $\mathrm{CF}$ bronchial epithelial (CFBE) cells were used. We tested ouabain, an ATP12A inhibitor that inhibits $\mathrm{H}^{+}$secretion by human epithelial cells, raising the $\mathrm{pH}$ value of cultured epithelial cells (Shah et al., 2016). Without any treatment, the ASL of cultured CFBE 
A

Biofilm Adaptation

Sterile Bead

P.a. Biofilm Colonized Bead

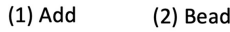

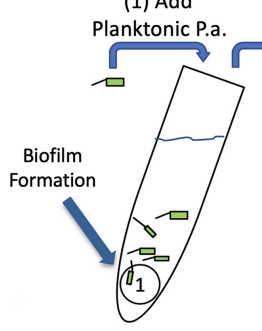

C

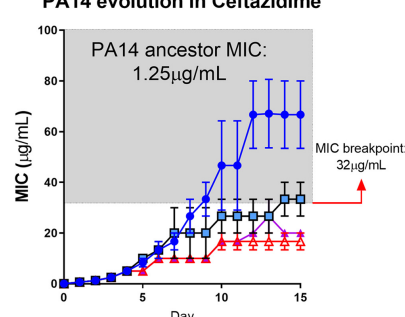

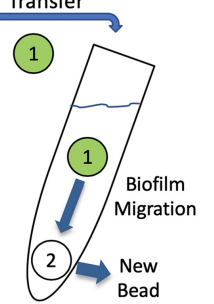

D PA14 evolution in Ciprofloxacin

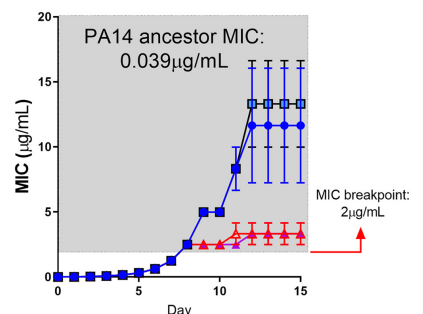

B Planktonic Adaptation

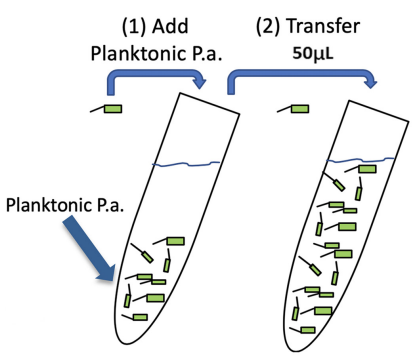

E

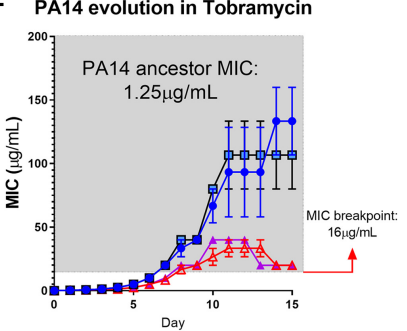

pH 6.5 Planktonic $\triangle \mathrm{pH} 7.5$ Biofilm $\longrightarrow \mathrm{pH} 7.5$ Planktonic

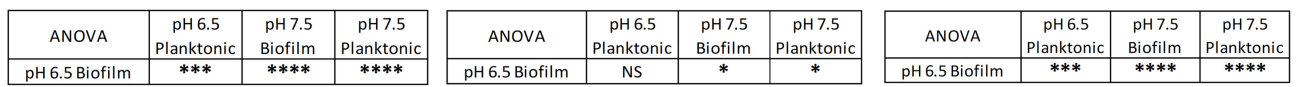

$\mathbf{F}$

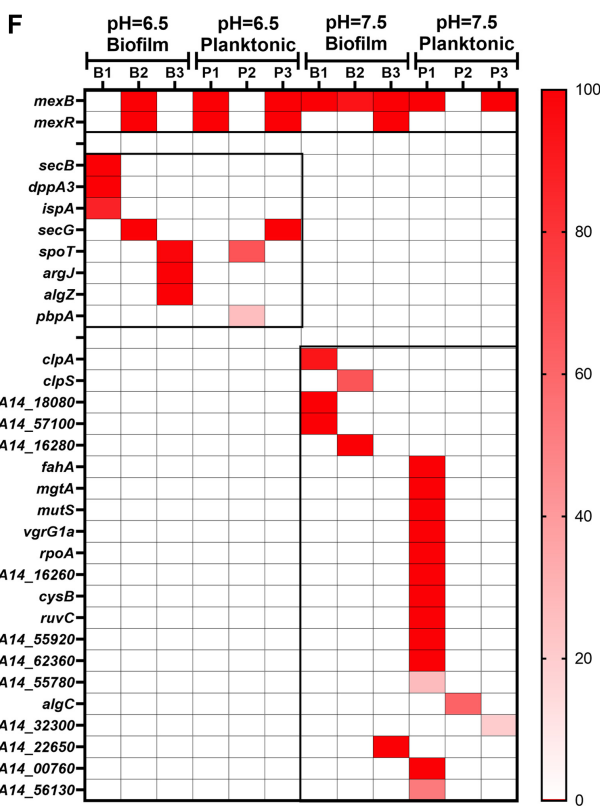

G Clonal mutations - Isolated from
pH 6.5 biofilm populations \#1-3

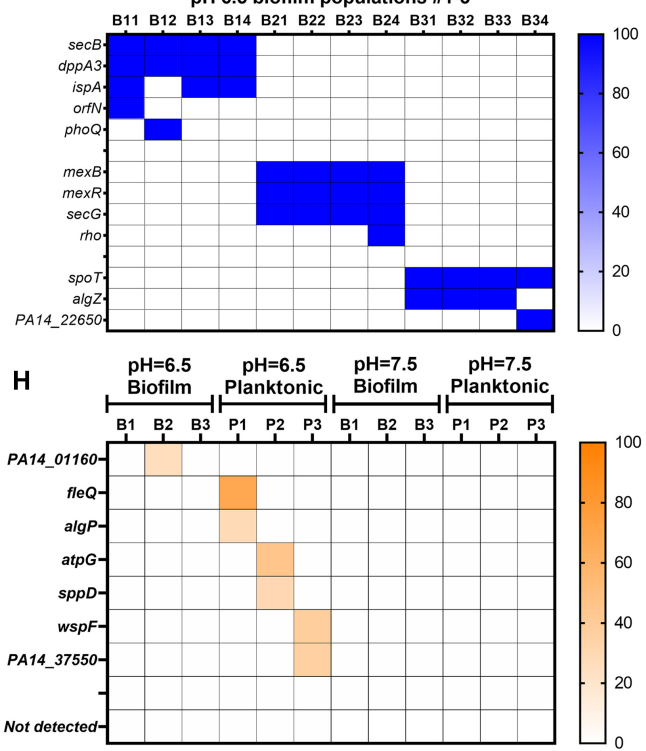

FIGURE 2 | Acidic pH promotes faster accumulation of adaptive resistance of $P$. aeruginosa against antibiotics compared to $\mathrm{pH} 7.5$. (A,B) Schematics of the P. aeruginosa PA14 antibiotic adaptation experiment: biofilm on beads $\mathbf{( A )}$ and planktonic bacteria (B) were transferred to fresh m63 media ( $\mathrm{pH}=6.5 / 7.5$, adjusted by $\mathrm{HCl}$ ) every $24 \mathrm{~h}$. (C-E) The PA14 biofilm/planktonic cultures were treated with 1/2 MIC at day 1 . Antibiotic concentrations were doubled after every bead/planktonic transfer $(n=3)$. The gray boxes on panels $(\mathbf{C}-\mathbf{E})$ denote MIC values that are considered antibiotic-resistant according to the guideline "MIC Breakpoints for Pseudomonas aeruginosa," published by The Clinical and Laboratory Standards Institute. (F) PA14 population mutations were identified after 15 days of evolution with ceftazidime. Each bacterial lifestyle/pH was evolved in triplicate populations. Biofilm (B)/planktonic (P) populations were labeled as B1, B2, B3, and P1, P2, P3, respectively. (G) Clonal mutations detected after 15 days of evolution with ceftazidime. Clones were labeled from number 1 to 4 following their population number. For example, B11 represents biofilm population B1, clone \#1. (H) Mutations from PA14 evolution without antibiotics for 15 days. Color scale bars represent mutation frequency, which ranges from 0 to 100\%. Data are mean \pm SEM. One-way ANOVA was performed by comparing the combined day 14 and 15 MIC values. ${ }^{*} p<0.05 ;{ }^{* * *} p<0.001 ; * * * p<0.0001 ;$ NS, not significant. 
TABLE 1 | PA14 clonal MIC from the ceftazidime evolution study*.

\begin{tabular}{|c|c|c|c|c|}
\hline \multirow[t]{2}{*}{ Population } & \multirow{2}{*}{$\begin{array}{l}\text { Clone } \\
\text { number }\end{array}$} & \multicolumn{2}{|c|}{ Clonal MIC (fold increase) } & \multirow{2}{*}{$\begin{array}{l}\mathrm{pH} \text {-induced } \\
\text { fold increase }\end{array}$} \\
\hline & & $\mathrm{pH} 6.5$ & pH 7.5 & \\
\hline \multirow{4}{*}{$\begin{array}{l}\text { Biofilm pH } 6.5 \\
\text { population } 1 \\
\text { (B1) }\end{array}$} & B11 & 64 & 4 & 16 \\
\hline & $\mathrm{B} 12$ & 80 & 4 & 20 \\
\hline & $\mathrm{B} 13$ & 64 & 4 & 16 \\
\hline & $\mathrm{B} 14$ & 94 & 6 & 15.7 \\
\hline \multirow{4}{*}{$\begin{array}{l}\text { Biofilm pH } 6.5 \\
\text { population } 2 \\
\text { (B2) }\end{array}$} & B21 & 96 & 10 & 9.6 \\
\hline & $\mathrm{B} 22$ & 96 & 24 & 4 \\
\hline & $\mathrm{B} 23$ & 96 & 24 & 4 \\
\hline & B24 & 128 & 32 & 4 \\
\hline \multirow{4}{*}{$\begin{array}{l}\text { Biofilm pH } 6.5 \\
\text { population } 3 \\
\text { (B3) }\end{array}$} & B31 & 6 & 4 & 1.5 \\
\hline & B32 & 4 & 4 & 1 \\
\hline & B33 & 6 & 4 & 1.5 \\
\hline & B34 & 8 & 4 & 2 \\
\hline
\end{tabular}

${ }^{*}$ Ceftazidime MIC against PA14 ancestor: $1.25 \mu \mathrm{g} / \mathrm{mL}$.

cells was more acidic than non-CF HBE cells (Figure 4B). However, ouabain successfully elevated the $\mathrm{pH}$ value of CFBE ASL from approximately 6.7 to 7.6 . The increased $\mathrm{pH}$ value reflected neutralized ASL of CFBE, which consequently resulted in decreased CFU of P. aeruginosa (PAO1) grew on top of human epithelial cells (Figure 4C). The ouabain modulation of $\mathrm{pH}$ in ASL of HBE was minimal, which did not result in significant changes of $P$. aeruginosa CFU (Figure 4C). Ouabain itself does not display any bactericidal activity at the treatment concentration of $20 \mu \mathrm{M}$ (Supplementary Figure S4).

\section{Bacterial Gene Expressions Are Modulated by Acidic pH}

To evaluate if acidic microenvironment-enhanced $P$. aeruginosa infection in CF is regulated through increased bacterial biofilm formation at the transcriptomic level, we determined the gene expression of a panel of biofilm/virulence-related genes (Figure 5A) in association with the observed biomass changes. Multiple biofilm-related genes such as tolA, $n d v B, r h l A$, and $r h l B$ were all significantly increased in the acidic conditions of biofilm formation.

Additionally, the expressions of several virulence-associated genes such as exoS, exoT, fimT, and fim X were also significantly increased in acidic environments ( $\mathrm{pH} 6.0$ and 6.5) compared to in physiological conditions ( $\mathrm{pH} 7.0$ and 7.5). Interestingly, the planktonic-associated mucB gene expression did not vary among all acidic and physiological biofilm-forming $\mathrm{pH}$ conditions. However, its expression differed significantly between the biofilm and planktonic forms of $P$. aeruginosa.

The rhlA and rhlB controlled rhamnolipid biosurfactant synthesis (Caiazza et al., 2005), and their gene expression data were validated by a bacterial swarming motility assay (Figure 5B). $P$. aeruginosa (PAO1) displayed significantly increased swarming diameter on acidic agar compared to $\mathrm{pH} 7.5$ agar. Similarly, the results from the follow-up twitching motility assay agreed with the elevated expression fim $T$ and $\operatorname{fim} \mathrm{X}$ in acidic $\mathrm{pH}$ conditions (Figure 5B).

\section{DISCUSSION}

Pseudomonas aeruginosa is the most dominant bacterial pathogen associated with CF disease severity and mortality. The CF microenvironment resulted from a CFTR malfunction may have an unwanted effect in contributing to the infection and colonization of $P$. aeruginosa. However, the underlying pathogenic mechanisms remain to be elucidated. In this study, we investigated the effect of CF-like acidic microenvironment on the behavior of $P$. aeruginosa. We demonstrated that multiple $P$. aeruginosa clinical isolates significantly increased their biofilm formation and antibiotic tolerance/resistance under acidic conditions. Remarkably, this pathological factor of acidic $\mathrm{pH}$ also activated a series of biofilm- and virulence-related genes of P. aeruginosa.

Under the selection pressure in an experimental condition with gradually increased antibiotic concentrations, we demonstrated that $P$. aeruginosa adapted to the antibiotics quickly and evolved significantly faster in $\mathrm{pH} 6.5$ than in $\mathrm{pH}$ 7.5, which eventually acquired strong antibiotic resistance in only 15 days [approximately 99 generations, estimated at 6.6 generations/day (Flynn et al., 2016)]. In contrast to the PA14 ancestor, evolved PA14 progeny bacteria demonstrated an indisputable ability to survive and adapt to highly stressful antibiotic treatments, while acidic $\mathrm{pH}$ significantly expedited this process. Of note, all of the frequently detected mexB mutations are single nucleotide polymorphisms (SNPs). These SNPs are not necessarily loss-of-function mutations, which would allow $P$. aeruginosa to maintain the MexAB-OprM efflux pump activities against ceftazidime. On the contrary, mutations on the mexR gene, a bacterial efflux pump repressor, are sometimes indels, which could lead to unsuppressed efflux pump activities. Both mechanisms likely contributed to the elevated PA14 ceftazidime resistance.

Our findings suggest that the acidic CF microenvironment likely plays a critical role in facilitating $P$. aeruginosa colonization despite the antibiotic treatment. Interestingly, $P$. aeruginosa appears to be the only bacterial species among the notorious MDR ESKAPE pathogens that displayed significantly increased biofilm formation under a CF-like acidic environment (Figure 3E), which may explain the high prevalence of $P$. aeruginosa in adult CF population when their airways are expected to be more acidic. Our data provide an important link between the worsened CFTR functionassociated acidic microenvironment and enhanced $P$. aeruginosa biofilm formation supported by the evidence of $P$. aeruginosa biofilm-related phenotypic/genetic changes and multiple microenvironment acidification factors.

It has been reported that the lowered airway $\mathrm{pH}$ is associated with impaired host defense mechanisms (Johansson et al., 1998; Zabner et al., 1998; Adewoye and Worobec, 1999; Nakayama et al., 2002; Abou Alaiwa et al., 2014; Shah et al., 2016; Tang et al., 2016). By neutralizing the acidic environment via inhibiting ATP12A, the apical $\mathrm{pH}$ value increased on the differentiated human primary airway epithelial cells (CFBE and non-CF HBE). The neutralized $\mathrm{pH}$ not only can potentially restore the antimicrobial activity of the naturally secreted host 
A

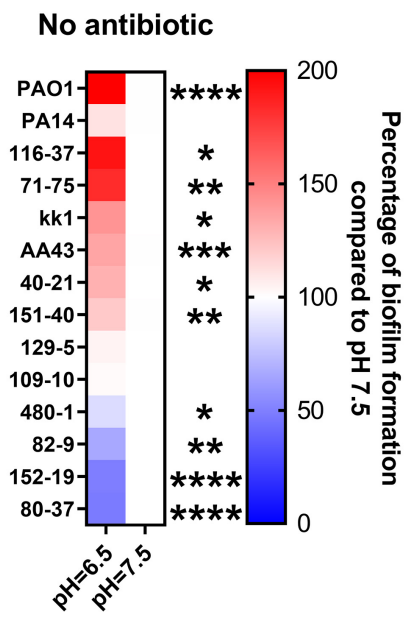

B

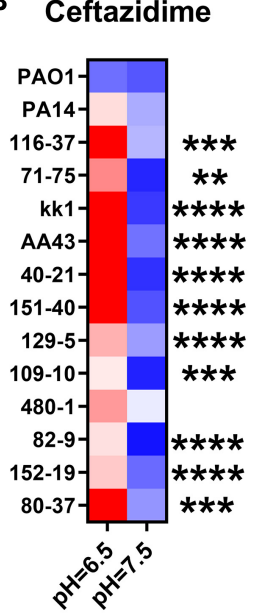

C

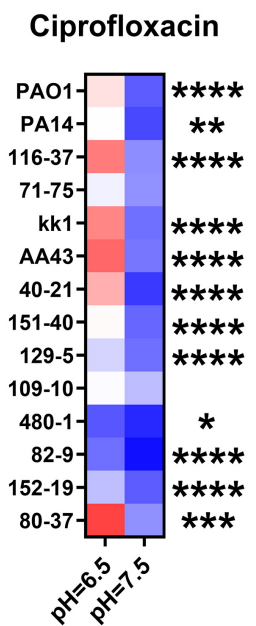

\section{Tobramycin}

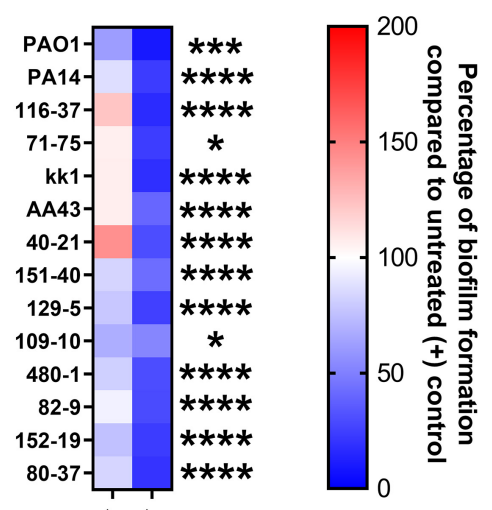

E
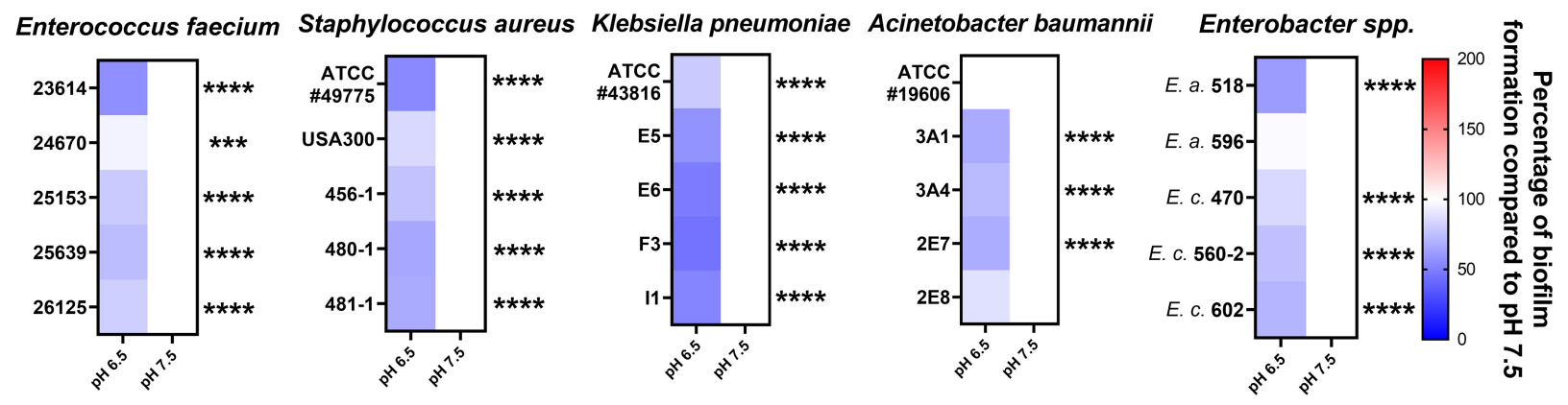

FIGURE 3 | Acidic pH modulates ESKAPE pathogens biofilm formation and impairs antibiotic biofilm prevention against $P$. aeruginosa. All $P$. aeruginosa strains (2 lab strains and 12 clinical strains) were incubated in $\mathrm{pH}$ adjusted $\mathrm{m} 63$ medium for $18 \mathrm{~h}$. The crystal violet staining method was used to quantify biofilm formation ( $n=6$ ). (A) P. aeruginosa biofilm formation without antibiotic treatment. Biofilm formation in $\mathrm{pH} 7.5$ served as a positive control. (B-D) P. aeruginosa biofilm formation was treated by ceftazidime, ciprofloxacin, and tobramycin at the concentrations of $1 \times$ MIC of each $P$. aeruginosa strain (MIC in normal pH 7.5 condition). The percentage of antibiotic-treated biofilm formation was calculated by comparing it to each untreated $P$. aeruginosa strain in $\mathrm{pH}$ 7.5. (E) Biofilm formation of other bacterial species of the ESKAPE bacterial pathogens. Five isolates from each of the other ESKAPE species were grown at pH 6.5 and 7.5 (as a control) in biofilm mode. E.a. and E.c. are abbreviations for Enterobacter aerogenes and Enterobacter cloacae, respectively. The color scale bars represent the percentage of biofilm formation compared to appropriate control groups. Red scale: increased biofilm formation (100\%-200\%); white: no change (100\%); blue scale: decreased biofilm formation (0-100\%). Data were collected from three independent experiments. Unpaired $t$-test was used for statistical analysis between each pH 6.5 and pH 7.5 conditions. ${ }^{*} p<0.05$; ${ }^{\star \star} p<0.01 ;{ }^{* \star} p<0.001 ;{ }^{* \star \star *} p<0.0001 ;$ otherwise not significant.

defense factors by airway epithelial cells such as SPLUNC1 (Di et al., 2013; Walton et al., 2016) but also may prevent biofilm formation and/or $\mathrm{pH}$-induced drug-tolerance/resistance of $P$. aeruginosa. These observations could provide potential therapeutic insights. For instance, there are several means to neutralize the acidic CF lung environment. By inhibiting ATP12A, the secretion of $\mathrm{H}^{+}$is inhibited, and therefore $\mathrm{pH}$ is elevated (Figure 4B). The extracellular $\mathrm{H}^{+}$could also be neutralized by commonly used substances, such as sodium bicarbonate (Wilton et al., 2016; Dobay et al., 2018) or hydroxide salts. The increased bacterial susceptibility to host factors after raising the acidic $\mathrm{pH}$ to neutral $\mathrm{pH}$ suggests an alternative approach in treating $\mathrm{CF}$ chronic infection induced by $P$. aeruginosa. Recent studies showed evidence that CFTR modulators, such as ivacaftor and lumacaftor-ivacaftor combination, increased the lung function of several genotypes of human CFTR mutations (Rowe et al., 2014; Caverly et al., 2015) and decreased $P$. aeruginosa lung culture positivity rates
(Heltshe et al., 2015). The increased CFTR activity reduces sweat $\mathrm{Cl}^{-}$, which may subsequently result in elevated ASL $\mathrm{pH}$ (Abou Alaiwa et al., 2018). However, the CFTR genotypes that are not covered by the CFTR modulators continue to be a challenge for $P$. aeruginosa management.

In addition to the efforts to neutralize the acidic host environment, it is also vital to examine the complex response of $P$. aeruginosa to acidic $\mathrm{pH}$ and how this response leads to antibiotic tolerance/resistance. Our gene expression results provided mechanistic insight into $\mathrm{pH}$-related pathways in pathogenic $P$. aeruginosa. Acidic conditions at $\mathrm{pH}$ values of 6 and 6.5 significantly increased the expression of tolA, activated in biofilms (Whiteley et al., 2001). Its product is responsible for aminoglycoside resistance in $P$. aeruginosa by decreasing its permeability and blocking the entrance of antibiotics (Bryan et al., 1976, 1980; Bryan and Kwan, 1983; Rivera et al., 1988; MacLeod et al., 2000). The $n d v B$ gene encodes for a glucosyltransferase that is required for the 


\section{A Experimental timeline}
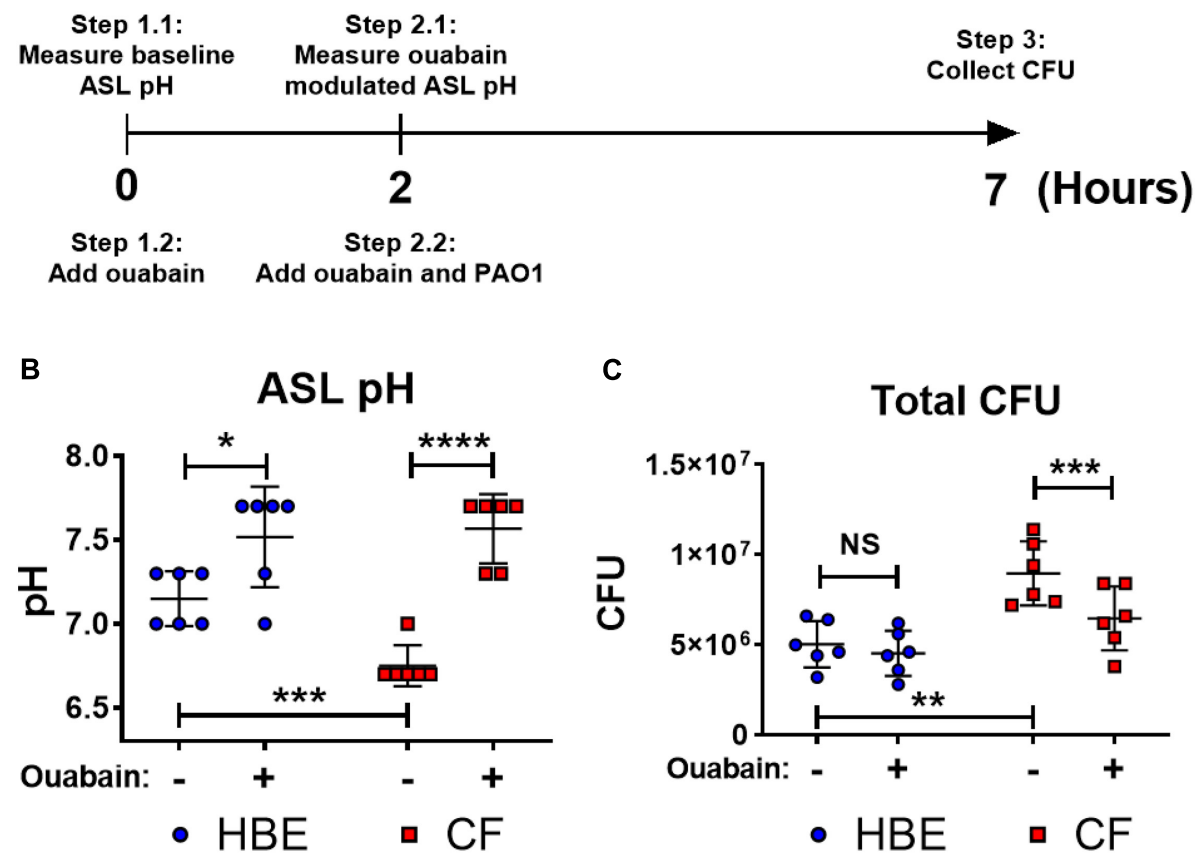

FIGURE 4 | Ouabain helps restore host defense activities by reversing the acidic $\mathrm{pH}$ to neutral pH in differentiated human bronchial epithelial cell cultures. (A) Experimental timeline. $\mathrm{pH}$ values were measured on the apical side of air-liquid interface cultured cells before and after $2 \mathrm{~h}$ of treatment with/without $20 \mathrm{\mu M}$ ouabain; PAO1 was then added to the apical side of cultured cells with ouabain or DMSO solvent control for additional $5 \mathrm{~h}$. (B) Effect of ouabain treatment on pH values in non-CF (HBE) and CF epithelial cells. The change of $\mathrm{pH}$ in the epithelial apical wash was measured by narrow range $\mathrm{pH}$ test strips ( $\mathrm{pH} 6-7.7$, resolution 0.3 $\mathrm{pH}$ unit; $n=6)$. (C) Effect of ouabain treatment on $P$. aeruginosa CFU in non-CF (HBE) and CF epithelial cells. PAO1 was incubated on the apical side of cultured $\mathrm{HBE}$ and CF epithelial cells in the existence of $20 \mu \mathrm{M}$ ouabain or DMSO (solvent control). Biofilm and planktonic CFU were obtained by plated on agar plates for total PAO1 CFU $(n=6)$. Data were collected from two independent experiments. Unpaired $t$-test was used for statistical analysis. Data are mean \pm SEM. ${ }^{*} p<0.05$; ${ }^{\star \star} p<0.01 ;{ }^{* \star \star} p<0.001 ;{ }^{\star \star \star \star} p<0.0001 ;$ NS, not significant.

synthesis of cyclic-b-(1, 3)-glucans (Bhagwat et al., 1996). Cyclic glucans can physically interact with tobramycin and therefore eliminate antibiotics before reaching their targeted site of action (Mah et al., 2003). In acidic conditions, there was a noticeably higher $n d v B$ gene expression in $P$. aeruginosa biofilm compared to the $\mathrm{pH} 7.5$ of physiological control. Planktonic form of PAO1 expressed significantly less $n d v B$ than any biofilm group. The elevated expression of $n d v B$ could be one factor contributing to the acidic $\mathrm{pH}$-induced antibiotic resistance in $P$. aeruginosa (Figures 1-4). Both $r h l A$ and $r h l B$ are required for rhamnolipid synthesis (Deziel et al., 2003), a biosurfactant that contributes to the swarming motility of $P$. aeruginosa to promote biofilm colonization. Rhamnolipids are known to interfere with phagocytosis (McClure and Schiller, 1996) and normal tracheal ciliary function (Read et al., 1992). The expression of these virulence factors was increased under the acidic $\mathrm{pH}$ environment. Both fimT and fimX are responsible for the biogenesis and functioning of type IV pili and twitching mobility of $P$. aeruginosa (Huang et al., 2003) and are crucial during biofilm formation (O'Toole and Kolter, 1998; Chiang and Burrows, 2003). P. aeruginosa injects cytotoxins (e.g., ExoS and ExoT) into host cells by utilizing the type III secretion system (Barbieri and Sun, 2004). Acidic pH conditions activated exoS and exoT will likely lead to delayed wound healing, impaired phagocytosis, and spread of $P$. aeruginosa (Hauser, 2009). The $m u c B$ gene is a negative regulator of the sigma factor AlgU. Inactivation of this gene in acidic conditions will facilitate the conversion of $P$. aeruginosa into alginate-producing mucoid forms (Martin et al., 1993; Boucher et al., 1997).

There is no consensus on whether or not the CF ASL is substantially more acidic than those in normal subjects. We have been able to consistently obtain more acidic $\mathrm{pH}$ measurements in human ALI bronchial epithelial cell culture derived from explanted lungs of CF patients than those from non-CF subjects (Figure 4B). However, some studies reported that they were unable to measure significant $\mathrm{pH}$ differences in ASL of children w/wo CF (Schultz et al., 2017), and the $\mathrm{pH}$ values were highly dependent on the $\mathrm{pH}$ probe materials and locations of the measurement (nasal or tracheal) (McShane et al., 2003). Nonetheless, it was reported that without the innate proton pump ATP12A activity and airway acidification, CFTR-deficient mice are free from opportunistic Staphylococcus aureus respiratory infection (Shah et al., 2016), which makes airway acidification the deciding factor of murine opportunistic lung infections. In addition, eDNA originated from the bacterial biofilm and human immune cells also contribute to the acidification of $\mathrm{CF}$ 
A
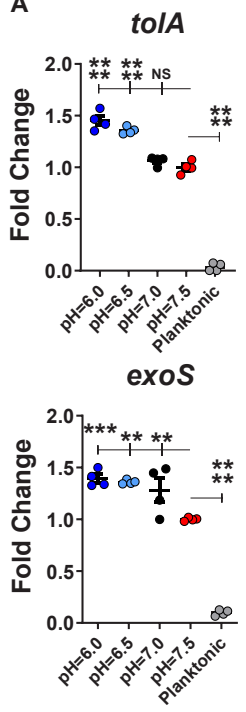

fimX
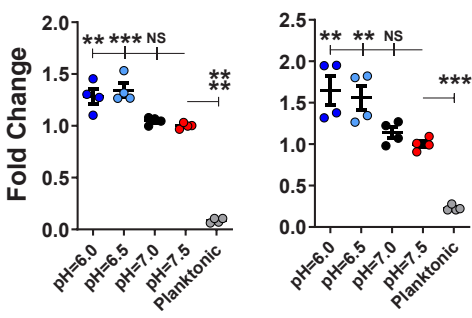

B

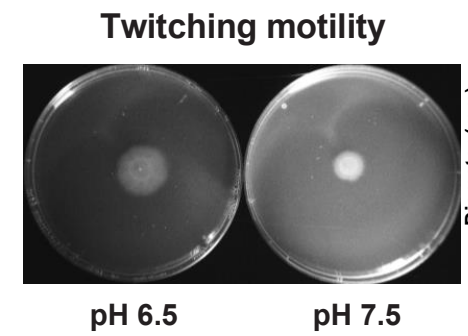

Swarming motility

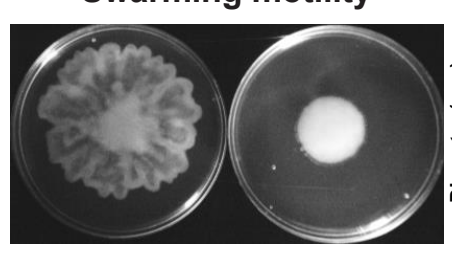

pH 6.5
mucB
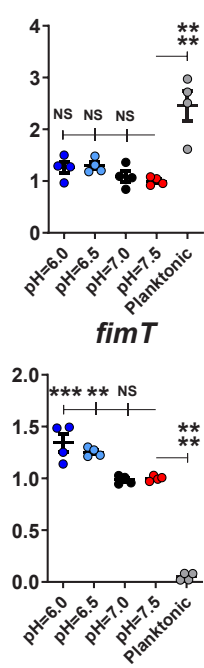

rhIB
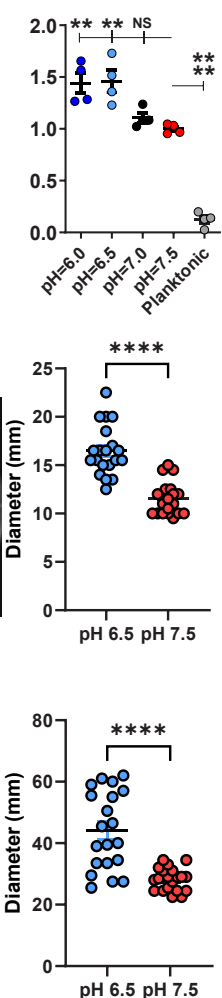

FIGURE 5 | Acidic pH conditions increase biofilm/virulence-related gene expression of $P$. aeruginosa. (A) $P$. aeruginosa PAO1 biofilm was cultured in $\mathrm{pH}$ adjusted DMEM for $3 \mathrm{~h}$. Physiologically related biofilm condition in $\mathrm{pH} 7.5$ was used as a control for biofilm growth. Planktonic form of $P$. aeruginosa inoculated in $\mathrm{pH} 7.5$ was also included for comparison $(n=4)$. (B) PAO1 motility assays. PAO1 swarming and twitching motility assays were performed on $\mathrm{pH}$ adjusted $\mathrm{M} 8$ agar $(n=20)$. Data were representative of two independent experiments. Results are mean \pm SEM. One-way ANOVA and Dunnett's multiple comparisons test were used for gene expression statistical analysis. Student's $t$-tests were used for bacterial motility assay statistical analysis ${ }^{\star} p<0.05 ;{ }^{* \star} p<0.01 ;{ }^{\star \star \star} p<0.001 ;{ }^{* \star \star *} p<0.0001$; NS, not significant.

microenvironments, which is evidenced by acidic $\mathrm{pH}$ gradients within $P$. aeruginosa biofilms (de los Rios et al., 2003; Hunter and Beveridge, 2005; Hidalgo et al., 2009) and acidified CF exhaled breath condensate (Tate et al., 2002; Ojoo et al., 2005), all of which are difficult to be discredited by the specific study using a direct ASL pH measurement in children, who are usually with less prominent CF phenotype and severity. Cowley et al. (2015) reported a $\mathrm{pH}$ range of 2.9 to 6.5 in pediatric CF sputum samples, which also disputes the notion that acidic $\mathrm{pH}$ is not a significant pathophysiological factor in CF. The CF microenvironment is much more complicated than what can be currently measured on human subjects. Our results are representative of the effects of an acidic environment on $P$. aeruginosa but do not address all abnormal CF conditions.

There are limitations to this study. We used the m63 medium for bacterial evolution experiments. M63 is a minimal medium that has been used for studying $P$. aeruginosa in $\mathrm{CF}$ (Wolfgang et al., 2004). We used D-glucose and $4 \mathrm{mM} \mathrm{L-}$ glutamine as the only nutrition sources in the m63 medium to maintain the $\mathrm{pH}$ consistency in simulating the CF-like acidic microenvironment. The synthetic cystic fibrosis sputum medium (SCFM) was developed to mimic the selective nutrient environment in the CF lungs (Palmer et al., 2007). However, we did not select SCFM for this study because it uses other amino acids, such as L-arginine, which causes an alkaline $\mathrm{pH}$ by releasing ammonia through deamination. While SCFM is a valuable tool in general CF-related studies, it remains an artificial medium and affects the acidic impact of cultivating P. aeruginosa. Therefore, we believe $\mathrm{m} 63$ is a more appropriate medium that consistently maintains acidic $\mathrm{pH}$ even after overnight bacterial culture. In our CFBE-ALI studies (Figure 4C), the PAO1 infected CFBE cells demonstrated a statistically significant decrease of CFU with ouabain treatment compared to normal saline control, but the averaged CFU number difference is relatively small. However, this is a proof of concept study. While the host-pathogen interaction model is more advanced than the conventional biofilm assay, this co-culture system still has limitations. For example, we could not incubate PAO1 on top of epithelial cells overnight to compare mature biofilm formation. Although the extended biofilm-forming period may show more substantial differences, the host cells would not be viable in the in vitro culture system after prolonged incubation with bacteria.

The choice between $P$. aeruginosa laboratory strains (PAO1 or PA14) throughout this study is justified for the following reasons. First, we used PAO1 instead of PA14 on CFBE-ALI studies because PA14 is highly virulent toward host cells by rapidly disrupting epithelial cell tight junction, as evidenced by our Trans-Epithelial Electrical Resistance (TEER) data (Supplementary Figure S5). PAO1 exhibits less acute virulence toward host cells compared to PA14 during the same time frame. Infecting epithelial cells with PAO1 better preserves the host cell integrity to facilitate the examination of biotic biofilm in the bacteria-host co-culture environment. Second, the ancestral PA14 did not increase its biofilm production under acidic $\mathrm{pH}$ without antibiotic pressure, but the PAO1 biofilm was significantly stimulated by acidic $\mathrm{pH}$ (Figure 3A 
and Supplementary Figure S2). It is commonly accepted that increased biofilm production contributes to antibiotic resistance. We determined that PA14 would be a better candidate for bacterial evolution in acidic $\mathrm{pH}$ to rule out the possibility that the rapidly accumulated antibiotic resistance is simply a result of increased biofilm formation.

We focused primarily on ceftazidime evolution and examined mutated PA14 at both population and clonal levels. We also sequenced the evolved PA14 populations from the ciprofloxacin or tobramycin treatments (Supplementary Figures S6A,B) at the end of the 15 days evolution and MIC monitoring (Figures 2D,E). In Supplementary Figure S6A, mutations on the $g y r A, n f x B$, and mor $A$ genes likely accounted for the primary resistance mechanism of PA14 toward ciprofloxacin in all 12 total populations (Wong et al., 2012; Ahmed et al., 2018; Farahi et al., 2018). Furthermore, we identified several specific mutations that existed only in an acidic environment (pilU, fliF, orf $N$, etc.). In Supplementary Figure S6B, tobramycin induced common mutations on fus $A$ and $r p l B$ genes, which are proven mutations that contribute to PA14 tobramycin resistance (Feng et al., 2016; Scribner et al., 2020). Unlike the PA14 ceftazidime evolution study results where acidic $\mathrm{pH}$ specific gene mutations contributed to antibiotic resistance, PA14 adapted to ciprofloxacin- and tobramycin-induced drug resistance by generating gene mutations in known mechanisms regardless of the $\mathrm{pH}$ conditions. These observations warrant further investigations on the mutation threshold of different classes of antibiotics. For instance, a single mutation on the PA14 gyrA gene could render ciprofloxacin useless while acidic $\mathrm{pH}$ promoted the resistance phenotypes even faster. The low cost of evolutionary trade-offs and easily mutated bacterial genome likely determine the performance of different antibiotics. Although the $\mathrm{pH}$-specific genes are not individually investigated in this study, they are viable candidates that could guide future research that focuses on the mechanisms of $\mathrm{pH}$-mediated bacterial drug resistance.

Of note, different culture media compositions could potentially impact antibiotic resistance and MIC results. For instance, Peng et al. (2015) provided evidence that higher exogenous alanine and/or glucose availability increases kanamycin susceptibility of some MDR pathogens. The underlying mechanism suggests that alanine or glucose promotes bacterial TCA cycle and proton motive force activity and, therefore, stimulates the bacterial intake of kanamycin. Such evidence suggests that bacterial culture media need to be carefully investigated before conducting drug-susceptibility tests. In this study, to appropriately measure bacterial growth curves with antibiotic treatment effects (Figure 1), which should include at least the first three phases of growth (lag phase, log phase, stationary phase, and death phase), we selected $\mathrm{pH}$-adjusted tryptic soy broth (TSB) instead of m63 as the culture media. Although the growth curve data using m63 demonstrated antibiotic MIC differences in various $\mathrm{pH}$ similar to those using TSB media (Figure 1), the bacterial culture did not always reach the stationary phase for all tested $P$. aeruginosa within the same 18-h timeframe (data not shown). This culture media switch did not affect our conclusions but improved bacterial optical density measurements in a microplate reader. Interestingly, our results indicated that the acidic $\mathrm{pH}$ consistently stimulated $\mathrm{PAO} 1$ biofilm overproduction regardless of the use of different culture media were similarly shown in a separate study using Mueller Hinton broth (MHB), Luria-Bertani broth (LB), and TSB under different environmental conditions (Khan et al., 2020). It was also shown that acidic $\mathrm{pH}$ could enhance in vitro biofilm formation of Streptococcus agalactiae (D'Urzo et al., 2014) that correlated to a hypervirulent strain. It would be interesting in future studies to extensively evaluate the magnitude of physiologically relevant $\mathrm{pH}$ conditions that affect the resistance of different human pathogen species, in addition to the ESKAPE strains we examined in this study.

This study was designed to explore the mechanisms of initial $P$. aeruginosa colonization and how the CF-specific lung microenvironment might contribute to this adverse health outcome. $P$. aeruginosa colonization in respiratory tracts is a chronic process, and the bacteria likely adapt and evolve in the CF lungs for decades. Longitudinal studies of the CF $P$. aeruginosa genotypes have illustrated that $P$. aeruginosa undergoes extensive genomic DNA mutations to survive in the CF lungs (Smith et al., 2006). Although many mutated genes have been identified, there was no connection between any previously identified mutations to the acidic $\mathrm{pH}$ environment. Our WGS data provided direct evidence that correlates acidic $\mathrm{pH}$-promoted bacterial drug resistance to short-term bacterial evolution. More studies are needed to target this aim and explore the role of acidic $\mathrm{pH}$ in long-term $P$. aeruginosa evolution/adaption to resolve the persistent biofilm formation and chronic colonization suffered by CF patients.

\section{MATERIALS AND METHODS}

\section{Bacterial Strains}

Clinical $P$. aeruginosa strains were isolated from pediatric CF patients with chronic pulmonary infections at Seattle Children's Research Institute except for AA43 and KK1 (Bragonzi et al., 2009), which were from a collection of the CF clinic at Medizinische Hochschule of Hannover, Germany. The lab strains used in this study were $P$. aeruginosa PAO1 (ATCC, BAA-47), UCBPP-PA14 (Rahme et al., 1995), Staphylococcus aureus ATCC\#49775, Klebsiella pneumoniae ATCC\#43816, and Acinetobacter baumannii ATCC\#19606. All other ESKAPE species were collected from patients at the University of Pittsburgh Medical Center or Seattle Children's Research Institute.

\section{Preparation of Pseudomonas aeruginosa}

All bacteria were retrieved from $-80^{\circ} \mathrm{C}$ glycerol stock and streaked on tryptic soy agar plates. Single colonies were picked and incubated in tryptic soy broth (TSB) overnight at $37^{\circ} \mathrm{C}$ in an orbital shaker. The overnight culture was diluted at 1:5 with fresh TSB and incubated for an additional $2 \mathrm{~h}$ for exponential growth. Bacteria were centrifuged at 2,000 $\times g$ for $5 \mathrm{~min}$. The pellet was resuspended in $1 \mathrm{ml}$ PBS. To ensure reproducible results, bacterial concentration was adjusted to approximately 
$10^{9} \mathrm{CFU} / \mathrm{mL}$, optical density $\left(\mathrm{OD}_{500 \mathrm{~nm}}\right)=0.5 \pm 0.01$ in a spectrophotometer.

\section{Bacterial Growth Inhibition Assay}

All GIA studies were performed in 10\% TSB diluted in PBS. The 96-well plate was incubated at $37^{\circ} \mathrm{C}$ in a microplate reader for $18 \mathrm{~h}$. Optical density (OD) at $570 \mathrm{~nm}$ was measured every hour with continuous double orbital shaking at 425 cycles per minute. The $\mathrm{pH}$ of the bacterial culture was adjusted to 6.0, 6.5, 7.0 , and 7.5 using hydrochloride acid $(\mathrm{HCl})$. The starting bacterial concentration in each treatment group was $10^{6} \mathrm{CFU} / \mathrm{mL}$. All pHadjusted media were filter-sterilized by a syringe filter unit (pore size: $0.22 \mu \mathrm{m}$, Millipore SLGP033RS) to ensure sterility.

\section{Biofilm Assay}

The crystal violet biofilm staining method developed by O'Toole (2011) was used in this study with slight modifications. All biofilm studies were performed in $\mathrm{pH}$ adjusted $\mathrm{m} 63$ medium supplemented with $1 \mathrm{mM} \mathrm{MgSO}_{4}, 25 \mu \mathrm{M} \mathrm{FeCl}_{3}, 40 \mathrm{mM}$ of Dglucose, and $4 \mathrm{mM}$ of L-glutamine. The $\mathrm{m} 63$ was supplemented with 10\% TSB to facilitate Staphylococcus aureus growth. The combination of D-glucose and L-glutamine allows the m63 to maintain its $\mathrm{pH}$ after $P$. aeruginosa overnight incubation. The testing bacterial concentrations were $5 \times 10^{7}$ and $10^{6} \mathrm{CFU} / \mathrm{ml}$ for biofilm formation and antibiotic biofilm prevention, respectively. After $18 \mathrm{~h}$ of biofilm formation in a humidified $37^{\circ} \mathrm{C}$ incubator (with or without antibiotic treatment), the supernatant was carefully removed by pipetting, and biofilm attached to the plate was stained with $0.5 \%$ crystal violet $(20 \%$ ethanol $+80 \%$ deionized water) solution for $15 \mathrm{~min}$. The excessive dye was then rinsed off with water, and $95 \%$ ethanol was added to release the dye from the biofilm. OD values were acquired by a microplate reader at $620 \mathrm{~nm}$ wavelength.

\section{Bacterial Evolution in Antibiotics}

Evolution studies were carried out using the m63 medium (same as biofilm assay). The bead transfer-based biofilm evolution model was described previously (Poltak and Cooper, 2011; Cooper, 2018; Jiang et al., 2019). Briefly, the PA14 ancestor was added to $5 \mathrm{~mL}$ of $\mathrm{pH}$ 6.5/7.5 m63 (media $\mathrm{pH}$ adjusted by $\mathrm{HCl}$ ) with $1 / 2 \mathrm{MIC}$ of antibiotic treatment at day 1 . After $24 \mathrm{~h}$, the PA14 biofilm (formed on a sterile acrylic bead) was transferred to the next tube of fresh m63 medium with a sterile bead inside. For planktonic culture, 50 uL of PA14 overnight culture was transferred to the next tube of fresh m63 medium. The dosage of antibiotics was doubled at the time of each transfer. The groups that survived antibiotic treatment were transferred to the next tube. The groups that could not tolerate the elevated antibiotic concentration were incubated again at the prior concentration without doubling antibiotic concentration.

\section{Bacterial Whole-Genome Sequencing}

Bacterial genomic DNA samples were extracted using the Qiagen DNeasy PowerBiofilm Kit. Biofilm attached to beads was dissociated by sonication in sterile PBS before DNA extraction.
Planktonic cultures were centrifuged and pelleted before DNA extraction. Library preparation (Baym et al., 2015; Turner et al., 2018) and WGS were performed by the University of Pittsburgh Microbial Genome Sequencing Center using Illumina NextSeq500.

\section{Bioinformatics}

Raw sequencing reads were quality filtered and trimmed by Trimmomatic (Bolger et al., 2014) using the following parameters: NexteraPE-PE.fa:2:30:10 LEADING:20 TRAILING:20 SLIDINGWINDOW:4:20 MINLEN:70. Genetic variants were predicted by breseq v0.33.0 (Deatherage and Barrick, 2014). The Pseudomonas aeruginosa UCBPP-PA14 reference genome was downloaded from NCBI. The PA14 ancestor clone was sequenced to eliminate background mutations. The sequencing depths of all evolved PA14 populations were at least $125 \times$. Mutation percentage higher than $20 \%$ are shown in the figures.

\section{Primary Airway Epithelial Cell Cultures}

Differentiated primary human bronchial epithelial cells were derived from lungs removed at the time of lung transplantation at the Center for Organ Recovery and Education (Pittsburgh, PA, United States). Cells were prepared using previously described methods (Liu et al., 2013a,b) approved by the University of Pittsburgh Institutional Review Board. Donor primary human $\mathrm{CF}$ and non-CF bronchial epithelial cells were first isolated from donor tissues and propagate under submerged cell culture. Upon confluence, epithelial cells were disassociated and seeded onto a transwell cell culture plate at approximately $2 \times 10^{5}$ cells/well (Corning, NY, United States). Epithelial cells were maintained in Bronchial Epithelial Cell Growth Medium (Lonza, Basel, Switzerland). The cell culture was changed to ALI by removing the apical medium 3 days after initial cell seeding and maintained for 3 weeks for cell differentiation.

\section{Treatment and Host Defense Activity of Primary Airway Epithelial Cell Cultures}

The $4 \mathrm{mM}$ ouabain stock solution was prepared and dissolved in DMSO. Ouabain was diluted to $20 \mu \mathrm{M}$ in normal saline and $20 \mu \mathrm{L}$ of the diluted ouabain or DMSO (vehicle control) was added to the primary cell cultures apically and incubated for $2 \mathrm{~h}$ in $37^{\circ} \mathrm{C}$ supplied with $5 \% \mathrm{CO}_{2}$. Primary cultured epithelial cells were washed apically with $100 \mu \mathrm{L}$ of PBS $24 \mathrm{~h}$ before the experiment. A total of $10 \mu \mathrm{L}$ of the apical fluid was immediately added onto $\mathrm{pH}$ test strips. After $\mathrm{pH}$ reading, all remaining apical fluid was removed, and another $20 \mu \mathrm{L}$ of $20 \mu \mathrm{M}$ ouabain or DMSO was added with $50 \mu \mathrm{L}$ of PAO1 suspended in normal saline ( $10^{7} \mathrm{CFU} /$ insert). Cells were then incubated for additional $5 \mathrm{~h}$ for biofilm to form. All apical supernatant was collected for determining the CFU of unattached planktonic bacteria. Biotic biofilm assay was used by counting CFU of bacterial biofilm formed on the epithelial cells. ALI membrane was removed from the filter and sonicated in $2 \mathrm{~mL}$ of PBS for $30 s$ at $80 \%$ amplitude by the DPS-20 dual processing system (130 W; PRO Scientific) to disassociate congregated 
PAO1 biofilm. After sonication, both planktonic and biofilm samples of PAO1 were plated on tryptic soy agar plates for total CFU counting.

\section{Gene Expression}

A total of $5 \times 10^{7} \mathrm{CFU} / \mathrm{mL}$ PAO1 was cultured in $\mathrm{pH}$-adjusted $(\mathrm{pH}=6.0,6.5,7.0$ and 7.5$)$ DMEM for $3 \mathrm{~h}$ in $100 \times 15 \mathrm{~mm}$ roundpetri dishes at $37^{\circ} \mathrm{C}$. For biofilm RNA samples, supernatant in all petri dishes was discarded and a thin layer of PAO1 biofilm was scraped off using a sterile cell scraper. The same amount of PAO1 was incubated separately in $5 \mathrm{~mL}$ of $\mathrm{pH} 7.5$ DMEM at the same time and served as a planktonic control. Total biofilm and planktonic RNA were extracted as previously published (Cury and Koo, 2007; Lin et al., 2018; Casciaro et al., 2019). The cDNA was synthesized by High-Capacity cDNA Reverse Transcription Kit (Applied Biosystems). Gene expression results were obtained using the Fast SYBR Green Master Mix (Applied Biosystems) and the 7900HT Fast RealTime PCR System (Applied Biosystems). $\Delta \Delta C_{t}$ values were calculated and analyzed using a method previously published (Lin and Di, 2020; Lin et al., 2021). The list of primers is listed in Supplementary Table S2.

\section{Bacterial Motility Assay}

Bacterial swarming and twitching motility assays were performed according to the protocols previously published (Ha et al., 2014; Turnbull and Whitchurch, 2014). $\mathrm{M} 8$ medium $\left(\mathrm{Na}_{2} \mathrm{HPO}_{4} \cdot 7 \mathrm{H}_{2} \mathrm{O}\right.$, supplemented with $0.5 \%$ casamino acids, $0.2 \%$ D-glucose, $1 \mathrm{mM}$ $\left.\mathrm{MgSO}_{4}\right)$ was used for agar preparation (0.5\% agar for swarming and $1.5 \%$ agar for twitching). Agar $\mathrm{pH}$ was adjusted to 7.5 and 6.5 by concentrated $\mathrm{HCl}$. The overnight culture of PAO1 was diluted to $10^{6} \mathrm{CFU} / \mathrm{mL}$. For swarming motility, $2.5 \mu \mathrm{L}$ of diluted PAO1 was dropped to the center of the agar. For twitching motility, a thin $10 \mu \mathrm{L}$ pipette tip was first dipped into the diluted PAO1, then punctured through the center of the agar. Plates were incubated at $37^{\circ} \mathrm{C}$ for $24 \mathrm{~h}$ before measurement.

\section{Measurement of Trans-Epithelial Electrical Resistance on Human Bronchial Epithelial Cell Cultures}

The human WT-CFTR bronchial epithelial cells were cultured in Minimum Essential Medium supplemented with 10\% fetal bovine serum and $0.5 \mu \mathrm{g} / \mathrm{mL}$ of puromycin in a $37^{\circ} \mathrm{C}$ incubator supplemented with $5 \% \mathrm{CO}_{2}$. A total of $2 \times 10^{5}$ cells were seeded on each ALI insert. The apical medium was removed after 3 days to convert to an air-liquid interface. Cells were used for TEER measurements after 7 days. The overnight cultures of PAO1 and PA14 were diluted in PBS to a final concentration of $10^{8} \mathrm{CFU} / \mathrm{mL}$. A total of $100 \mu \mathrm{L}$ diluted bacteria were added to the apical side of the ALI. TEER was measured using the Millicell ${ }^{\circledR}$ ERS-2 Voltohmmeter (Millipore Sigma, MERS00002).

\section{Statistical Analysis}

Error bars represent mean \pm standard error of the mean (SEM). One-way analysis of variance (ANOVA) and Tukey's multiple comparisons tests were used to assess the overall change of MIC in the bacterial evolution model. One-way ANOVA and Dunnett's multiple comparisons test were used to assess the change of bacterial gene expressions among various $\mathrm{pH}$ conditions. Two-way ANOVA and Dunnett's multiple comparisons test were used to assess the effects of $\mathrm{pH}$ and salt on bacterial biofilm formation. Student's $t$-test was used to assess statistical significance between two subjects, such as biofilm formation and antibiotic biofilm prevention in different $\mathrm{pH}$, human ALI ASL $\mathrm{pH}$, and CFU with or without ouabain treatment. ${ }^{*} p<0.05 ;{ }^{* *} p<0.01$; ${ }^{* * *} p<0.001$; ${ }^{* * * *} p<0.0001$; otherwise not significant (NS).

\section{DATA AVAILABILITY STATEMENT}

The sequencing data have been deposited with links to BioProject accession number PRJNA685187 in the NCBI BioProject database (https://www.ncbi.nlm.nih.gov/bioproject/ PRJNA685187).

\section{ETHICS STATEMENT}

The studies using primary non-CF and CF HBE cells obtained from explanted lungs of patients with written informed consent under a protocol reviewed and approved by the Institutional Review Board at the University of Pittsburgh.

\section{AUTHOR CONTRIBUTIONS}

YD contributed to the conceptualization, funding acquisition, and supervision. QL, JP, and YD contributed to the methodology. $\mathrm{QL}$ and YD contributed to the investigation. QL contributed to the writing - original draft. JP and YD contributed to the writing - review and editing and resources. All authors contributed to the article and approved the submitted version.

\section{FUNDING}

This work was supported by the National Institutes of Health (R01 AI-133351 to YD). The funding agencies had no role in study design, data collection, and analysis, decision to publish, or preparation of the manuscript.

\section{ACKNOWLEDGMENTS}

We thank Dr. Michael M. Myerburg for providing the primary human CF and non-CF bronchial epithelial cells.

\section{SUPPLEMENTARY MATERIAL}

The Supplementary Material for this article can be found online at: https://www.frontiersin.org/articles/10.3389/fmicb.2021. 747834/full\#supplementary-material 


\section{REFERENCES}

Abou Alaiwa, M. H., Launspach, J. L., Grogan, B., Carter, S., Zabner, J., Stoltz, D. A., et al. (2018). Ivacaftor-induced sweat chloride reductions correlate with increases in airway surface liquid $\mathrm{pH}$ in cystic fibrosis. JCI Insight 3:e121468. doi: 10.1172 /jci.insight. 121468

Abou Alaiwa, M. H., Reznikov, L. R., Gansemer, N. D., Sheets, K. A., Horswill, A. R., Stoltz, D. A., et al. (2014). pH modulates the activity and synergism of the airway surface liquid antimicrobials beta-defensin-3 and LL-37. Proc. Natl. Acad. Sci. U.S.A. 111, 18703-18708. doi: 10.1073/pnas.1422091112

Adewoye, L. O., and Worobec, E. A. (1999). Multiple environmental factors regulate the expression of the carbohydrate-selective OprB porin of Pseudomonas aeruginosa. Can. J. Microbiol. 45, 1033-1042. doi: 10.1139/ w99-110

Ahmed, M. N., Porse, A., Sommer, M. O. A., Hoiby, N., and Ciofu, O. (2018). Evolution of antibiotic resistance in biofilm and planktonic Pseudomonas aeruginosa populations exposed to subinhibitory levels of ciprofloxacin. Antimicrob. Agents Chemother. 62:e00320-18. doi: 10.1128/AAC.00320-18

Barbieri, J. T., and Sun, J. (2004). Pseudomonas aeruginosa ExoS and ExoT. Rev. Physiol. Biochem. Pharmacol. 152, 79-92. doi: 10.1007/s10254-004-0031-7

Baym, M., Kryazhimskiy, S., Lieberman, T. D., Chung, H., Desai, M. M., and Kishony, R. (2015). Inexpensive multiplexed library preparation for megabasesized genomes. PLoS One 10:e0128036. doi: 10.1371/journal.pone.0128036

Bhagwat, A. A., Gross, K. C., Tully, R. E., and Keister, D. L. (1996). Beta-glucan synthesis in Bradyrhizobium japonicum: characterization of a new locus (ndvC). influencing beta-(1->6). linkages. J. Bacteriol. 178, 4635-4642. doi: 10.1128/jb. 178.15.4635-4642.1996

Bolger, A. M., Lohse, M., and Usadel, B. (2014). Trimmomatic: a flexible trimmer for Illumina sequence data. Bioinformatics 30, 2114-2120. doi: 10.1093/ bioinformatics/btul70

Boucher, J. C., Schurr, M. J., Yu, H., Rowen, D. W., and Deretic, V. (1997). Pseudomonas aeruginosa in cystic fibrosis: role of mucC in the regulation of alginate production and stress sensitivity. Microbiology 143(Pt 11), 3473-3480. doi: 10.1099/00221287-143-11-3473

Bragonzi, A., Paroni, M., Nonis, A., Cramer, N., Montanari, S., Rejman, J., et al. (2009). Pseudomonas aeruginosa microevolution during cystic fibrosis lung infection establishes clones with adapted virulence. Am. J. Respir. Crit. Care Med. 180, 138-145. doi: 10.1164/rccm.200812-1943OC

Bryan, L. E., Haraphongse, R., and Van den Elzen, H. M. (1976). Gentamicin resistance in clinical-isolates of Pseudomonas aeruginosa associated with diminished gentamicin accumulation and no detectable enzymatic modification. J. Antibiot. 29, 743-753. doi: 10.7164/antibiotics.29.743

Bryan, L. E., and Kwan, S. (1983). Roles of ribosomal binding, membrane potential, and electron transport in bacterial uptake of streptomycin and gentamicin. Antimicrob. Agents Chemother. 23, 835-845. doi: 10.1128/AAC.23.6.835

Bryan, L. E., Nicas, T., Holloway, B. W., and Crowther, C. (1980). Aminoglycosideresistant mutation of Pseudomonas aeruginosa defective in cytochrome c552 and nitrate reductase. Antimicrob. Agents Chemother. 17, 71-79. doi: 10.1128/ AAC.17.1.71

Caiazza, N. C., Shanks, R. M., and O’Toole, G. A. (2005). Rhamnolipids modulate swarming motility patterns of Pseudomonas aeruginosa. J. Bacteriol. 187, 73517361. doi: 10.1128/JB.187.21.7351-7361.2005

Casciaro, B., Lin, Q., Afonin, S., Loffredo, M. R., de Turris, V., Middel, V., et al. (2019). Inhibition of Pseudomonas aeruginosa biofilm formation and expression of virulence genes by selective epimerization in the peptide esculentin-1a(121)NH2. FEBS J. 286, 3874-3891. doi: 10.1111/febs. 14940

Caverly, L. J., Zhao, J., and LiPuma, J. J. (2015). Cystic fibrosis lung microbiome: opportunities to reconsider management of airway infection. Pediatr. Pulmonol. 50(Suppl. 40), S31-S38. doi: 10.1002/ppul.23243

Chen, J. H., Stoltz, D. A., Karp, P. H., Ernst, S. E., Pezzulo, A. A., Moninger, T. O., et al. (2010). Loss of anion transport without increased sodium absorption characterizes newborn porcine cystic fibrosis airway epithelia. Cell 143, 911923. doi: 10.1016/j.cell.2010.11.029

Chiang, P., and Burrows, L. L. (2003). Biofilm formation by hyperpiliated mutants of Pseudomonas aeruginosa. J. Bacteriol. 185, 2374-2378. doi: 10.1128/JB.185. 7.2374-2378.2003

Cooper, V. S. (2018). Experimental evolution as a high-throughput screen for genetic adaptations. mSphere 3:e00121-18.
Cowley, E. S., Kopf, S. H., LaRiviere, A., Ziebis, W., and Newman, D. K. (2015). Pediatric cystic fibrosis sputum can be chemically dynamic, anoxic, and extremely reduced due to hydrogen sulfide formation. mBio 6:e00767. doi: 10.1128/mBio.00767-15

Cury, J. A., and Koo, H. (2007). Extraction and purification of total RNA from Streptococcus mutans biofilms. Anal. Biochem. 365, 208-214. doi: 10.1016/j.ab. 2007.03.021

Cystic Fibrosis Foundation (2020). 2019 Annual Data Report. Bethesda, MD: Cystic Fibrosis Foundation Patient Registry.

D’Urzo, N., Martinelli, M., Pezzicoli, A., De Cesare, V., Pinto, V., Margarit, I., et al. (2014). Members of the, acidic ph strongly enhances in vitro biofilm formation by a subset of hypervirulent ST-17 Streptococcus agalactiae strains. Appl. Environ. Microbiol. 80, 2176-2185. doi: 10.1128/AEM.03627-13

de los Rios, A., Wierzchos, J., Sancho, L. G., and Ascaso, C. (2003). Acid microenvironments in microbial biofilms of Antarctic endolithic microecosystems. Environ. Microbiol. 5, 231-237. doi: 10.1046/j.1462-2920. 2003.00417.x

Deatherage, D. E., and Barrick, J. E. (2014). Identification of mutations in laboratory-evolved microbes from next-generation sequencing data using breseq. Methods Mol. Biol. 1151, 165-188. doi: 10.1007/978-1-4939-0554-6_12

Deziel, E., Lepine, F., Milot, S., and Villemur, R. (2003). rhlA is required for the production of a novel biosurfactant promoting swarming motility in Pseudomonas aeruginosa: 3-(3-hydroxyalkanoyloxy)alkanoic acids (HAAs), the precursors of rhamnolipids. Microbiology 149, 2005-2013. doi: 10.1099/mic.0. 26154-0

Di, Y. P., Tkach, A. V., Yanamala, N., Stanley, S., Gao, S., Shurin, M. R., et al. (2013). Dual acute pro-inflammatory and anti-fibrotic pulmonary effects of SPLUNC1 after exposure to carbon nanotubes. Am. J. Respir. Cell Mol. Biol. 49, 759-767.

Dobay, O., Laub, K., Stercz, B., Keri, A., Balazs, B., Tothpal, A., et al. (2018). Bicarbonate inhibits bacterial growth and biofilm formation of prevalent cystic fibrosis pathogens. Front. Microbiol. 9:2245. doi: 10.3389/fmicb.2018.02245

Ernst, R. K., Moskowitz, S. M., Emerson, J. C., Kraig, G. M., Adams, K. N., Harvey, M. D., et al. (2007). Unique lipid a modifications in Pseudomonas aeruginosa isolated from the airways of patients with cystic fibrosis. J. Infect. Dis. 196, 1088-1092. doi: 10.1086/521367

Farahi, R. M., Ali, A. A., and Gharavi, S. (2018). Characterization of gyrA and parC mutations in ciprofloxacin-resistant Pseudomonas aeruginosa isolates from Tehran hospitals in Iran. Iran. J. Microbiol. 10, 242-249.

Feng, Y., Jonker, M. J., Moustakas, I., Brul, S., and Ter Kuile, B. H. (2016). Dynamics of mutations during development of resistance by Pseudomonas aeruginosa against five antibiotics. Antimicrob. Agents Chemother. 60, 4229-4236. doi: 10.1128/AAC.00434- 16

Flynn, K. M., Dowell, G., Johnson, T. M., Koestler, B. J., Waters, C. M., and Cooper, V. S. (2016). Evolution of ecological diversity in biofilms of Pseudomonas aeruginosa by altered cyclic diguanylate signaling. J. Bacteriol. 198, 2608-2618. doi: 10.1128/JB.00048-16

Ha, D. G., Kuchma, S. L., and O’Toole, G. A. (2014). Plate-based assay for swarming motility in Pseudomonas aeruginosa. Methods Mol. Biol. 1149, 67-72. doi: 10.1007/978-1-4939-0473-0_8

Hauser, A. R. (2009). The type III secretion system of Pseudomonas aeruginosa: infection by injection. Nat. Rev. Microbiol. 7, 654-665. doi: 10.1038/ nrmicro2199

Heltshe, S. L., Mayer-Hamblett, N., Burns, J. L., Khan, U., Baines, A., Ramsey, B. W., et al. (2015). Pseudomonas aeruginosa in cystic fibrosis patients with G551D-CFTR treated with ivacaftor. Clin. Infect. Dis. 60, 703-712. doi: 10. 1093/cid/ciu944

Hidalgo, G., Burns, A., Herz, E., Hay, A. G., Houston, P. L., Wiesner, U., et al. (2009). Functional tomographic fluorescence imaging of $\mathrm{pH}$ microenvironments in microbial biofilms by use of silica nanoparticle sensors. Appl. Environ. Microbiol. 75, 7426-7435. doi: 10.1128/AEM.01220-09

Huang, B., Whitchurch, C. B., and Mattick, J. S. (2003). FimX, a multidomain protein connecting environmental signals to twitching motility in Pseudomonas aeruginosa. J. Bacteriol. 185, 7068-7076. doi: 10.1128/JB.185.24.7068-7076. 2003

Hunter, R. C., and Beveridge, T. J. (2005). Application of a pH-sensitive fluoroprobe (C-SNARF-4). for $\mathrm{pH}$ microenvironment analysis in Pseudomonas aeruginosa biofilms. Appl. Environ. Microbiol. 71, 2501-2510. doi: 10.1128/ AEM.71.5.2501-2510.2005 
Jiang, S., Deslouches, B., Chen, C., Di, M. E., and Di, Y. P. (2019). Antibacterial properties and efficacy of a novel SPLUNC1-derived antimicrobial peptide, alpha4-short, in a murine model of respiratory infection. mBio 10:e00226-19. doi: 10.1128/mBio.00226-19

Johansson, J., Gudmundsson, G. H., Rottenberg, M. E., Berndt, K. D., and Agerberth, B. (1998). Conformation-dependent antibacterial activity of the naturally occurring human peptide LL-37. J. Biol. Chem. 273, 3718-3724. doi: 10.1074/jbc.273.6.3718

Johnson, L., Mulcahy, H., Kanevets, U., Shi, Y., and Lewenza, S. (2012). Surfacelocalized spermidine protects the Pseudomonas aeruginosa outer membrane from antibiotic treatment and oxidative stress. J. Bacteriol. 194, 813-826. doi: 10.1128/JB.05230-11

Khan, F., Lee, J. W., Pham, D. T. N., Lee, J. H., Kim, H. W., Kim, Y. K., et al. (2020). Streptomycin mediated biofilm inhibition and suppression of virulence properties in Pseudomonas aeruginosa PAO1. Appl. Microbiol. Biotechnol. 104, 799-816. doi: 10.1007/s00253-019-10190-w

Lethem, M. I., James, S. L., Marriott, C., and Burke, J. F. (1990). The origin of DNA associated with mucus glycoproteins in cystic fibrosis sputum. Eur. Respir. J. 3, $19-23$.

Lin, Q., and Di, Y. P. (2020). Determination and quantification of bacterial virulent gene expression using quantitative real-time PCR. Methods Mol. Biol. 2102, 177-193. doi: 10.1007/978-1-0716-0223-2_9

Lin, Q., Deslouches, B., Montelaro, R. C., and Di, Y. P. (2018). Prevention of ESKAPE pathogen biofilm formation by antimicrobial peptides WLBU2 and LL37. Int. J. Antimicrob. Agents 52, 667-672. doi: 10.1016/j.ijantimicag.2018. 04.019

Lin, Q., Zhang, X., Yang, D., Liu, C. H., Huleihel, L., Remlinger, N., et al. (2021). Treatment with a urinary bladder matrix alters the innate host response to pneumonia induced by Escherichia coli. ACS Biomater. Sci. Eng. 7, 1088-1099. doi: 10.1021/acsbiomaterials.0c01090

Liu, Y., Bartlett, J. A., Di, M. E., Bomberger, J. M., Chan, Y. R., Gakhar, L., et al. (2013a). SPLUNC1/BPIFA1 contributes to pulmonary host defense against Klebsiella pneumoniae respiratory infection. Am. J. Pathol. 182, 1519-1531. doi: 10.1016/j.ajpath.2013.01.050

Liu, Y., Di, M. E., Chu, H. W., Liu, X., Wang, L., Wenzel, S., et al. (2013b). Increased susceptibility to pulmonary Pseudomonas infection in Splunc1 knockout mice. J. Immunol. 191, 4259-4268. doi: 10.4049/jimmunol.1202340

Lyczak, J. B., Cannon, C. L., and Pier, G. B. (2002). Lung infections associated with cystic fibrosis. Clin. Microbiol. Rev. 15, 194-222.

MacLeod, D. L., Nelson, L. E., Shawar, R. M., Lin, B. B., Lockwood, L. G., Dirk, J. E., et al. (2000). Aminoglycoside-resistance mechanisms for cystic fibrosis Pseudomonas aeruginosa isolates are unchanged by long-term, intermittent, inhaled tobramycin treatment. J. Infect. Dis. 181, 1180-1184. doi: 10.1086/ 315312

Mah, T. F., Pitts, B., Pellock, B., Walker, G. C., Stewart, P. S., and O’Toole, G. A. (2003). A genetic basis for Pseudomonas aeruginosa biofilm antibiotic resistance. Nature 426, 306-310. doi: 10.1038/nature02122

Martin, D. W., Schurr, M. J., Mudd, M. H., and Deretic, V. (1993). Differentiation of Pseudomonas aeruginosa into the alginate-producing form: inactivation of mucB causes conversion to mucoidy. Mol. Microbiol. 9, 497-506. doi: 10.1111/ j.1365-2958.1993.tb01711.x

Matsukawa, M., and Greenberg, E. P. (2004). Putative exopolysaccharide synthesis genes influence Pseudomonas aeruginosa biofilm development. J. Bacteriol. 186, 4449-4456. doi: 10.1128/JB.186.14.4449-4456.2004

Mayer-Hamblett, N., Kronmal, R. A., Gibson, R. L., Rosenfeld, M., Retsch-Bogart, G., Treggiari, M. M., et al. (2012). Initial Pseudomonas aeruginosa treatment failure is associated with exacerbations in cystic fibrosis. Pediatr. Pulmonol. 47, 125-134. doi: 10.1002/ppul.21525

McClure, C. D., and Schiller, N. L. (1996). Inhibition of macrophage phagocytosis by Pseudomonas aeruginosa rhamnolipids in vitro and in vivo. Curr. Microbiol. 33, 109-117. doi: 10.1007/s002849900084

McShane, D., Davies, J. C., Davies, M. G., Bush, A., Geddes, D. M., and Alton, E. W. (2003). Airway surface $\mathrm{pH}$ in subjects with cystic fibrosis. Eur. Respir. J. 21,37-42. doi: 10.1183/09031936.03.00027603

Nakayama, K., Jia, Y. X., Hirai, H., Shinkawa, M., Yamaya, M., Sekizawa, K., et al. (2002). Acid stimulation reduces bactericidal activity of surface liquid in cultured human airway epithelial cells. Am. J. Respir. Cell Mol. Biol. 26, 105-113. doi: $10.1165 / \mathrm{ajrcmb} .26 .1 .4425$
O’Toole, G. A. (2011). Microtiter dish biofilm formation assay. J. Vis. Exp. 47:2437. O’Toole, G. A., and Kolter, R. (1998). Flagellar and twitching motility are necessary for Pseudomonas aeruginosa biofilm development. Mol. Microbiol. 30, 295-304. doi: 10.1046/j.1365-2958.1998.01062.x

Ojoo, J. C., Mulrennan, S. A., Kastelik, J. A., Morice, A. H., and Redington, A. E. (2005). Exhaled breath condensate $\mathrm{pH}$ and exhaled nitric oxide in allergic asthma and in cystic fibrosis. Thorax 60, 22-26. doi: 10.1136/thx.2003. 017327

Okshevsky, M., and Meyer, R. L. (2015). The role of extracellular DNA in the establishment, maintenance and perpetuation of bacterial biofilms. Crit. Rev. Microbiol. 41, 341-352. doi: 10.3109/1040841X.2013.841639

Palmer, K. L., Aye, L. M., and Whiteley, M. (2007). Nutritional cues control Pseudomonas aeruginosa multicellular behavior in cystic fibrosis sputum. J. Bacteriol. 189, 8079-8087. doi: 10.1128/JB.01138-07

Peng, B., Su, Y. B., Li, H., Han, Y., Guo, C., Tian, Y. M., et al. (2015). Exogenous alanine and/or glucose plus kanamycin kills antibiotic-resistant bacteria. Cell Metab. 21, 249-262. doi: 10.1016/j.cmet.2015.01.008

Pezzulo, A. A., Tang, X. X., Hoegger, M. J., Abou Alaiwa, M. H., Ramachandran, S., Moninger, T. O., et al. (2012). Reduced airway surface $\mathrm{pH}$ impairs bacterial killing in the porcine cystic fibrosis lung. Nature 487, 109-113. doi: 10.1038/ nature 11130

Poltak, S. R., and Cooper, V. S. (2011). Ecological succession in long-term experimentally evolved biofilms produces synergistic communities. ISME J. 5 , 369-378. doi: 10.1038/ismej.2010.136

Rahme, L. G., Stevens, E. J., Wolfort, S. F., Shao, J., Tompkins, R. G., and Ausubel, F. M. (1995). Common virulence factors for bacterial pathogenicity in plants and animals. Science 268, 1899-1902. doi: 10.1126/science.7604262

Read, R. C., Roberts, P., Munro, N., Rutman, A., Hastie, A., Shryock, T., et al. (1992). Effect of Pseudomonas aeruginosa rhamnolipids on mucociliary transport and ciliary beating. J. Appl. Physiol. 72, 2271-2277. doi: 10.1152/jappl. 1992.72.6.2271

Rivera, M., Hancock, R. E., Sawyer, J. G., Haug, A., and McGroarty, E. J. (1988). Enhanced binding of polycationic antibiotics to lipopolysaccharide from an aminoglycoside-supersusceptible, tolA mutant strain of Pseudomonas aeruginosa. Antimicrob. Agents Chemother. 32, 649-655. doi: 10.1128/AAC.32. 5.649

Rowe, S. M., Heltshe, S. L., Gonska, T., Donaldson, S. H., Borowitz, D., Gelfond, D., et al. (2014). Clinical mechanism of the cystic fibrosis transmembrane conductance regulator potentiator ivacaftor in G551D-mediated cystic fibrosis. Am. J. Respir. Crit. Care Med. 190, 175-184. doi: 10.1164/rccm.201404-0703OC

Sanz-Garcia, F., Hernando-Amado, S., and Martinez, J. L. (2018). Mutation-driven evolution of Pseudomonas aeruginosa in the presence of either ceftazidime or ceftazidime-avibactam. Antimicrob. Agents Chemother. 62:e01379-18.

Schultz, A., Puvvadi, R., Borisov, S. M., Shaw, N. C., Klimant, I., Berry, L. J., et al. (2017). Airway surface liquid $\mathrm{pH}$ is not acidic in children with cystic fibrosis. Nat. Commun. 8:1409.

Scribner, M. R., Santos-Lopez, A., Marshall, C. W., Deitrick, C., and Cooper, V. S. (2020). Parallel evolution of tobramycin resistance across species and environments. mBio 11:e00932-20. doi: 10.1128/mBio.00932-20

Shah, V. S., Meyerholz, D. K., Tang, X. X., Reznikov, L., Abou Alaiwa, M., Ernst, S. E., et al. (2016). Airway acidification initiates host defense abnormalities in cystic fibrosis mice. Science 351, 503-507. doi: 10.1126/science.aad5589

Silva Filho, L. V., Ferreira Fde, A., Reis, F. J., Britto, M. C., Levy, C. E., Clark, O., et al. (2013). Pseudomonas aeruginosa infection in patients with cystic fibrosis: scientific evidence regarding clinical impact, diagnosis, and treatment. J. Bras. Pneumol. 39, 495-512. doi: 10.1590/S1806-37132013000400015

Smith, E. E., Buckley, D. G., Wu, Z., Saenphimmachak, C., Hoffman, L. R., D'Argenio, D. A., et al. (2006). Genetic adaptation by Pseudomonas aeruginosa to the airways of cystic fibrosis patients. Proc. NatL. Acad. Sci. U.S.A. 103, 8487-8492.

Tang, X. X., Ostedgaard, L. S., Hoegger, M. J., Moninger, T. O., Karp, P. H., McMenimen, J. D., et al. (2016). Acidic pH increases airway surface liquid viscosity in cystic fibrosis. J. Clin. Invest. 126, 879-891. doi: 10.1172/JCI83922

Tate, S., MacGregor, G., Davis, M., Innes, J. A., and Greening, A. P. (2002). Airways in cystic fibrosis are acidified: detection by exhaled breath condensate. Thorax 57, 926-929. doi: 10.1136/thorax.57.11.926

Turnbull, L., and Whitchurch, C. B. (2014). Motility assay: twitching motility. Methods Mol. Biol. 1149, 73-86. doi: 10.1007/978-1-4939-0473-0_9 
Turner, C. B., Marshall, C. W., and Cooper, V. S. (2018). Parallel genetic adaptation across environments differing in mode of growth or resource availability. Evol. Lett. 2, 355-367.

Walton, W. G., Ahmad, S., Little, M. S., Kim, C. S., Tyrrell, J., Lin, Q., et al. (2016). Structural features essential to the antimicrobial functions of human SPLUNC1. Biochemistry 55, 2979-2991. doi: 10.1021/acs.biochem.6b00271

Whiteley, M., Bangera, M. G., Bumgarner, R. E., Parsek, M. R., Teitzel, G. M., Lory, S., et al. (2001). Gene expression in Pseudomonas aeruginosa biofilms. Nature $413,860-864$.

Wilton, M., Charron-Mazenod, L., Moore, R., and Lewenza, S. (2016). Extracellular DNA acidifies biofilms and induces aminoglycoside resistance in Pseudomonas aeruginosa. Antimicrob. Agents Chemother. 60, 544-553. doi: 10.1128/AAC. 01650- 15

Wolfgang, M. C., Jyot, J., Goodman, A. L., Ramphal, R., and Lory, S. (2004). Pseudomonas aeruginosa regulates flagellin expression as part of a global response to airway fluid from cystic fibrosis patients. Proc. Natl. Acad. Sci. U.S.A. 101, 6664-6668. doi: 10.1073/pnas.0307553101

Wong, A., Rodrigue, N., and Kassen, R. (2012). Genomics of adaptation during experimental evolution of the opportunistic pathogen Pseudomonas aeruginosa. PLoS Genet. 8:e1002928. doi: 10.1371/journal.pgen.1002928
Zabner, J., Smith, J. J., Karp, P. H., Widdicombe, J. H., and Welsh, M. J. (1998) Loss of CFTR chloride channels alters salt absorption by cystic fibrosis airway epithelia in vitro. Mol. Cell 2, 397-403. doi: 10.1016/s1097-2765(00)80284-1

Conflict of Interest: The authors declare that the research was conducted in the absence of any commercial or financial relationships that could be construed as a potential conflict of interest.

Publisher's Note: All claims expressed in this article are solely those of the authors and do not necessarily represent those of their affiliated organizations, or those of the publisher, the editors and the reviewers. Any product that may be evaluated in this article, or claim that may be made by its manufacturer, is not guaranteed or endorsed by the publisher.

Copyright (C) 2021 Lin, Pilewski and Di. This is an open-access article distributed under the terms of the Creative Commons Attribution License (CC BY). The use, distribution or reproduction in other forums is permitted, provided the original author(s) and the copyright owner(s) are credited and that the original publication in this journal is cited, in accordance with accepted academic practice. No use, distribution or reproduction is permitted which does not comply with these terms. 